تحليل فرسايندگى باد و يتانسيل حمل ماسههاى روان واقع در قلمرو بيابان لوت

نوع مقاله: يثوهشى

ساسان زنخنه تبار: دانشجوى دكترى ثئومورفولوزى، دانشكدمى جغرافيا، دانشكاه تهران، تهران

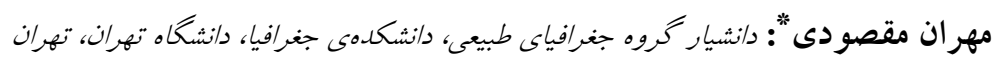
فاطمه منبرى: دانشجوى دكترى ثئومورفولوثى، دانشكدهى ادبيات و علوم انسانى، دانشكاه رانى، كرمانشاه

جكيده

در اين تحقيق به منظور بررسى جهت باد و يتانسيل حمل ماسه در سطح بيابان لوت، از آمار ·r سالهى جهار ايستگاه سينو يتيك بم، شهداد، نهبندان و نصرت آباد استفاده شد. تحليل اين دادهها، در نرمافزارهاى ويندروز و سندروز انجام شد. نتايج بر اين دلالت داشت كه غالب بادها در ايستخاههاى شهداد و نهبنـدان از جهـات شـمالى مىوزند، اما در ايستخاههاى بم و نصرت آباد به سمت لوت متمر كز مىشوند. تطبيـق نتـايج گـلطوفـان و گـل ماسهها نشان مىدهد كه جهت بادهاى ايستخاههاى شهداد و بم با جهت شمالغربى - جنوبش شرقى كلوتك هـاى واقع در غرب بيابان لوت انطباق كامل دارد و در شرق لوت جايى كه ريخ وسيع يلان قـرار دارد، بادهـاى دو ايستخاه نهبندان و نصرت آباد كاملاً مخالف هم هستند كه شرايط لازم را براى تشكيل هرمهاى ماسهاى در مركز اين ريخ فراهم مى كند. در ايستخاههاى بم و شهداد، بالاترين يتانسيل حمل ماسه (DP) مربوط به جهات شمال و شمالشرقى و در ايستگاه شهداد، جهات مابين غرب تا شمالشرقى است؛ در حالى كه در ايستگاه نصرت آباد، جهت آن كاملاً نسبت به ساير ايستخاهها متفاوت و بالاترين مقدار آن مربوط به جهات جنوب و جنسوب غربسى است. مجموع توان حمل ماسه (DPt) نيز به ترتيب به ايستخاههاى شهداد، نهبندان، نصرت آباد و بم اختصـاص دارد. بالاترين مقدار بردار برآيند توان حمل ماسه (RDP)؛ مربوط بـه ايسـتگاه شهـداد اسـت و بعـد از آن بـه. ترتيب ايستگاههاى نهبندان، نصرت آباد و بم قرار دارند. بررسى شاخص همخنس جهـت حمـل ماسـ (UDI)، بيانكر بادهاى يك جهته در ايستگاه نهبندان و بادهاى دو جهته با زاويلى منفرجه در ايستخاههاى بـم، شهـداد و نصرت آباد است. بيشترين مقدار دبى حمل ماسه مربـوط بـه ايستخكاه شـهداد و كمتـرين ميـزان آن مربـوط بـه ايستخاه نصرت آباد است. بيشترين مقدار كل ماسهى حمل شده (TSF) بهترتيب بـه ايستكاه شهداد، نهبنـدان، نصرت آباد و بم تعلق دارد. بيشترين مقدار بر آيند حمل ماسه (DSF) نيز به ترتيب به ايستگاه شهداد، نهبنـدان، بم و نصرت آباد بازمى گردد. واز كان كليدى: باد، يتانسيل حمل ماسه، فرسايندگى، لوتى 
مناطق خشك و نيمه خشك جهان بيش از ·ـ درصد سطح زمين را در برمى گيرد (Okin et al, 2006). باد به عنوان يكى از عوامل فرسايشدهندهى سطح زمين، به حمل ماسهها و تغيير شكل در مناطق خشك منجــر مسى شـود. عوامـل

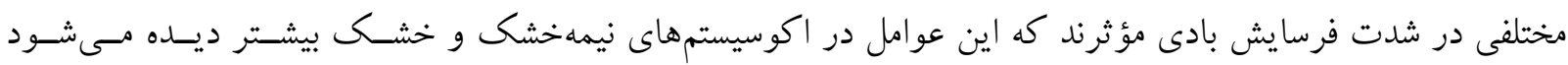

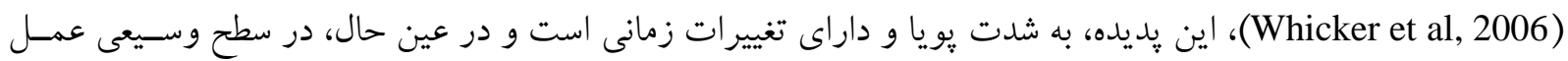

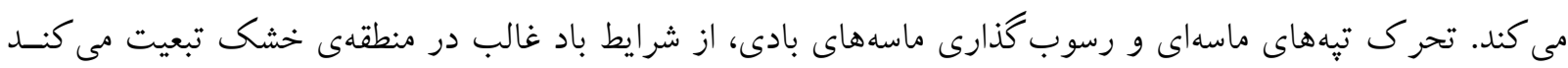
(Lancaster, 1995 \& Lettau, 1978 \& Tsoar, 1994) باد است و در كنترل شدت فرسايش بادى نقش مهمسى دارد (Skidmore, 1987 \& Zhuodong Zhang et al, 2012). در واقع، فرسايش بادى ارتباط مستقيمى با سرعت باد دارد و هر خه سرعت باد بيش از مقدار آستانه باشد، افزايش ايـن

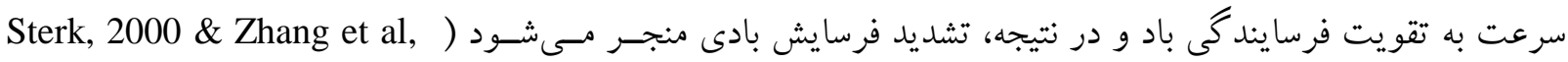

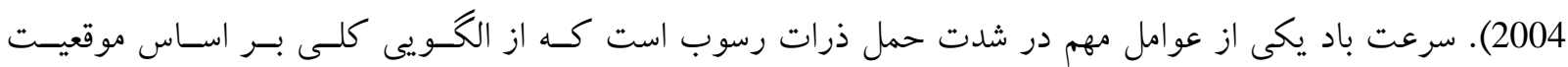

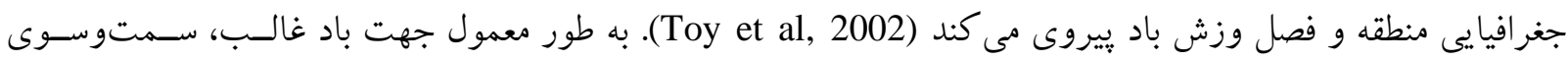
جابهجايى بيشترين مقدار ذرات رسوب را تعيين مى كند (Skidmore, 1987). حركت باد و تغيير يذيرى جهت ونى آن، تأثير

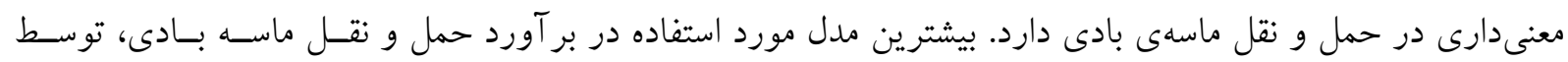

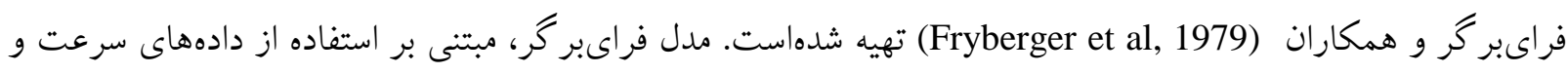

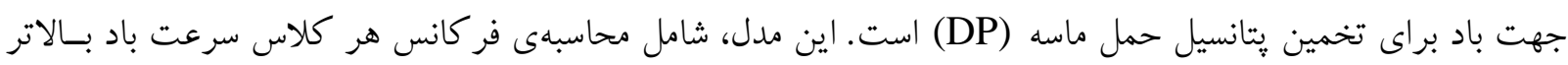

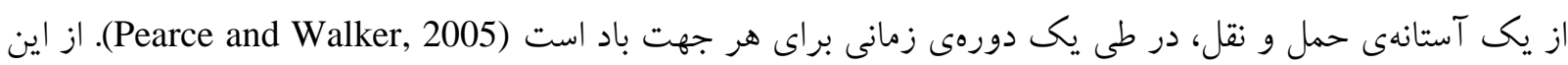

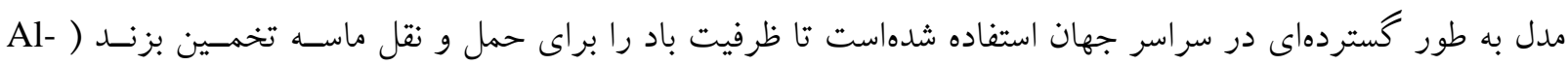
Awadhi and Al-Dousari, 2013 \& Livingstone et al, 2010 \& Zhengcai Zhang et al, 2015 دليل قرار كرفتن بر روى كمربند خشك نيمكرهى شمالى، يكى از مناطق حساس دنيـا در برابـر فرسـايش بــادى اسـت

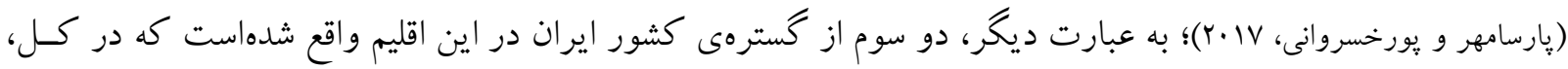

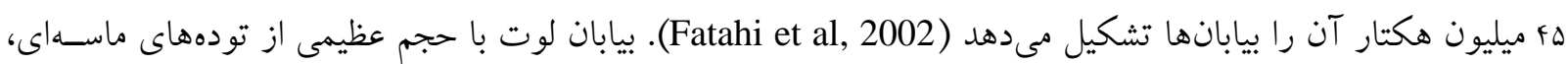

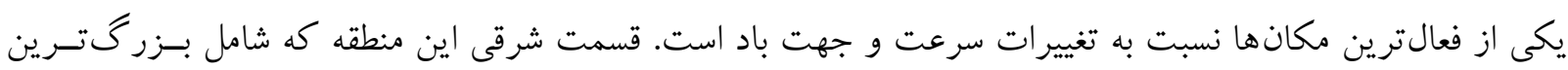

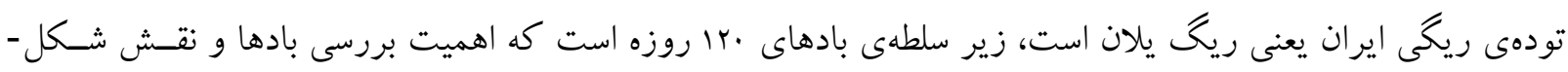

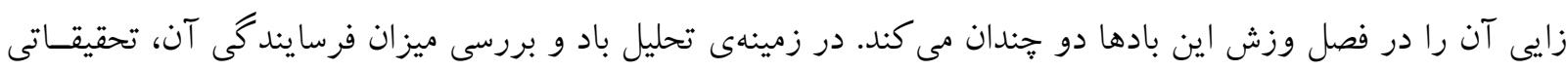

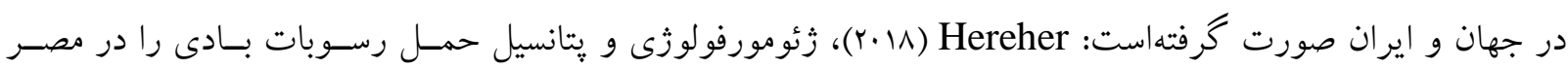
بررسى كرد و دريافت كه رسوبات قابلتوجهى از ماسهاى بادى، در محيطهاى بادى كم انرزى با تسلط تبههاى عرضى

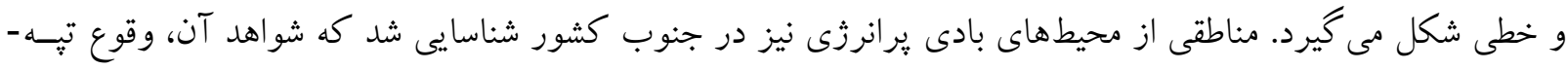

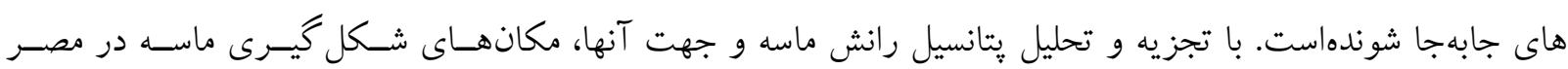

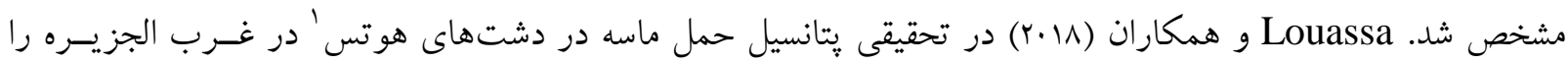

\footnotetext{
${ }^{1}$ Hautes
} 


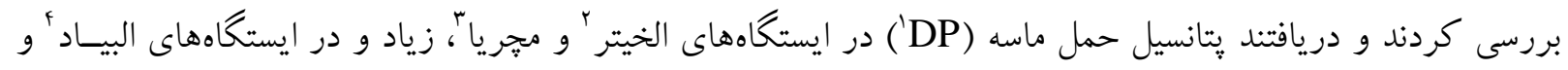

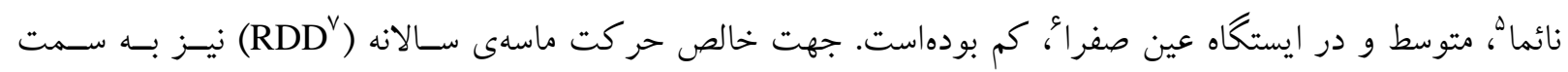

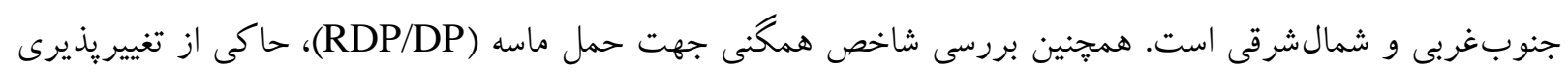

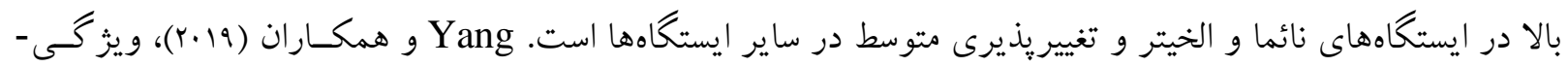

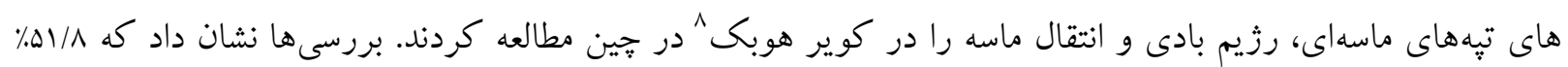

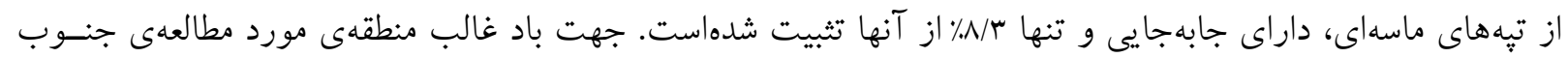

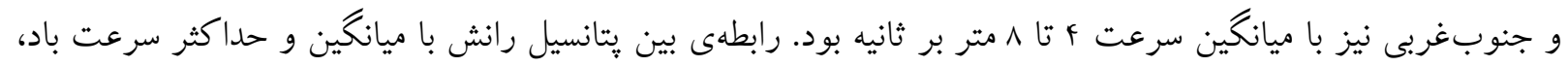

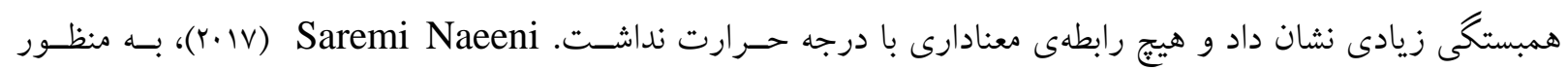

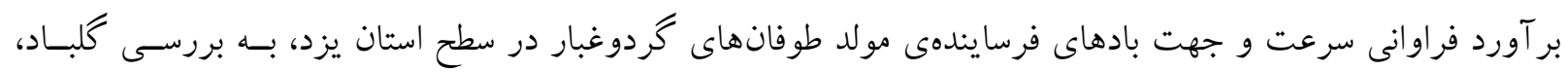

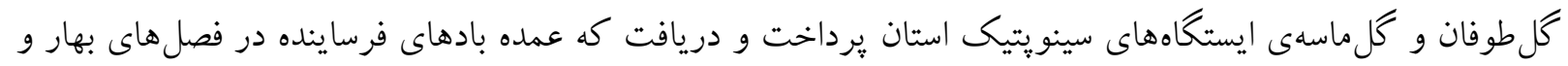

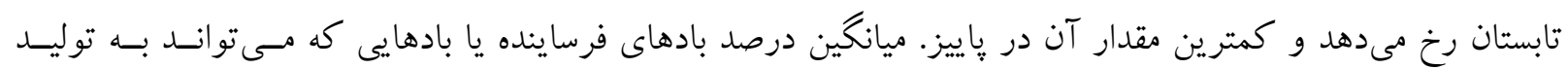

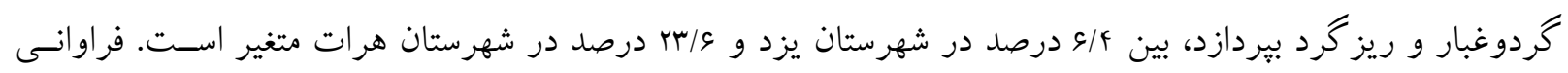

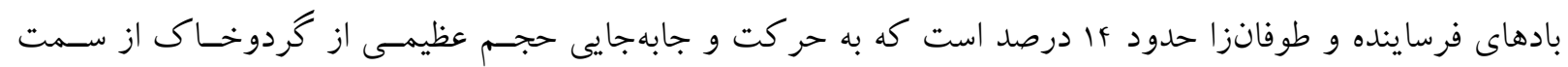

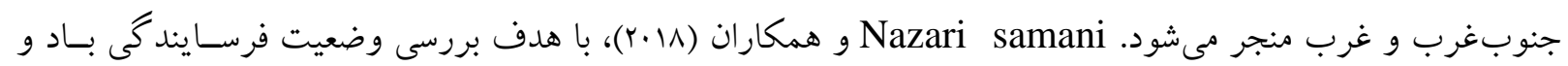

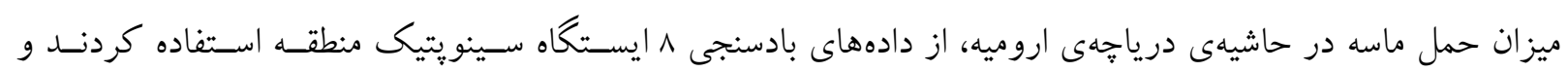

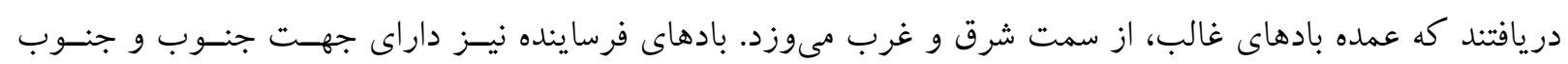

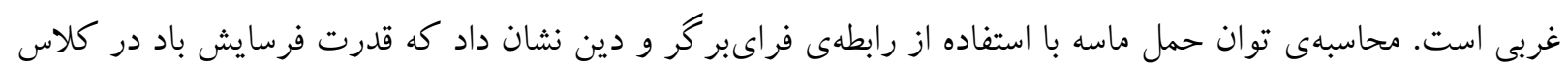

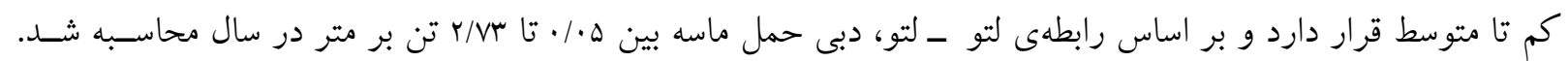

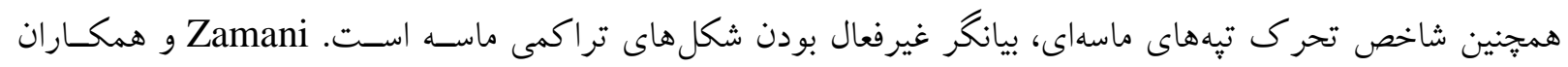

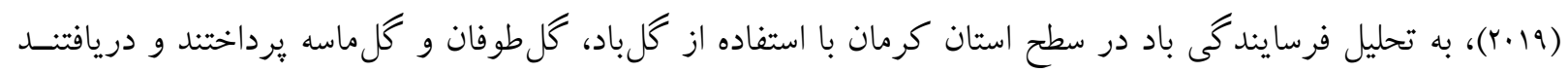

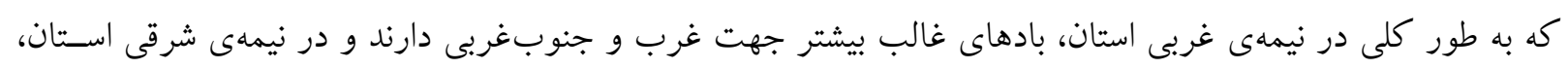

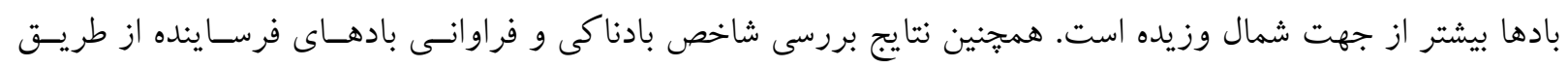

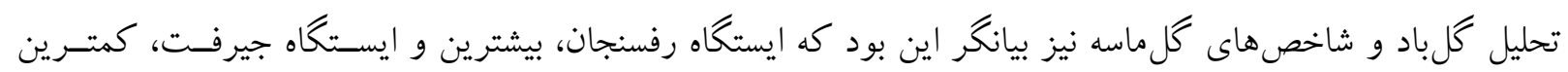
بادهاى فرساينده و طوفانزا را دارد. هدف اصلى اين تحقيق، تحليل جهت و فراوانى بادهاى فرساينده و بررسى ارتباط آن با زئومورفولوزى اشكال بادى

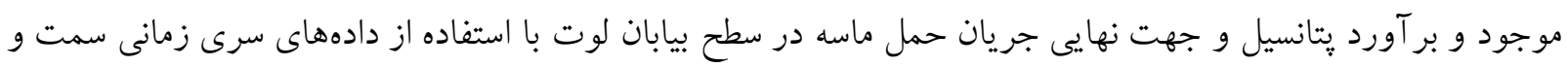

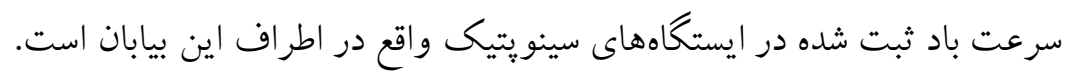

\footnotetext{
${ }^{1}$ Drift Potential

${ }^{2}$ El-Kheither

${ }^{3}$ Mecheria

${ }^{4}$ El-Bayadh

${ }^{5}$ Naama

${ }^{6}$ Ain-Sefra

${ }^{7}$ Resultant Drift Direction

${ }^{8}$ Hobq
} 


\section{r - منطقهى مورد مطالعه}

بيابان لوت در جنوب شرقى ايران، در شرق كوههاى مركزى و رشته كوههاى زاكرس، در ميان سه اسـتان خراسـان

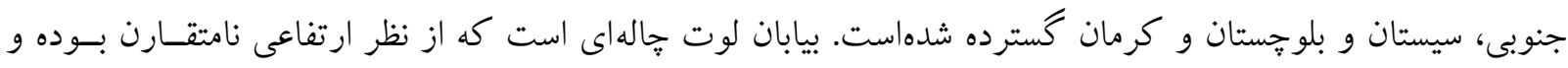

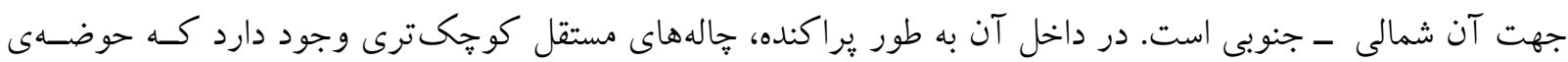
انتهايى آبهاى روان است. در اين تحقيق، بخشى از بيابان لوت ـ كه به عنوان ميراث جهانى اين بيابان ثبت شدهاسـت

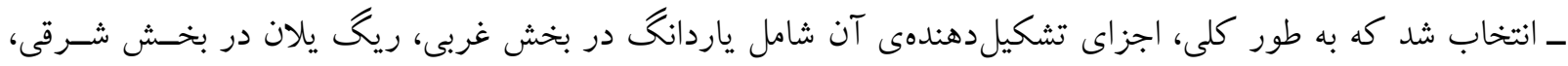

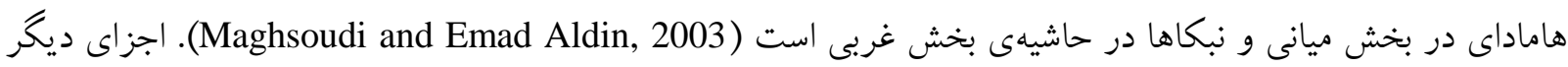

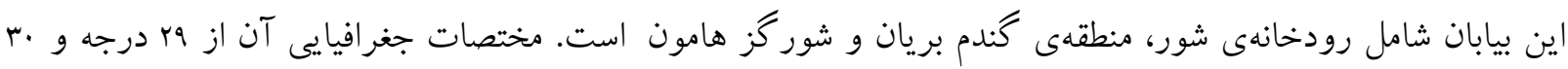

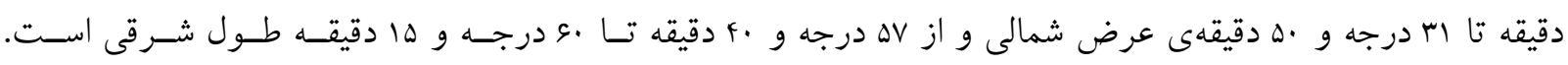

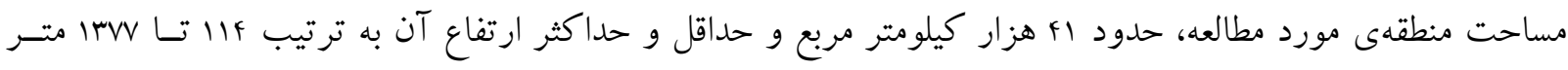

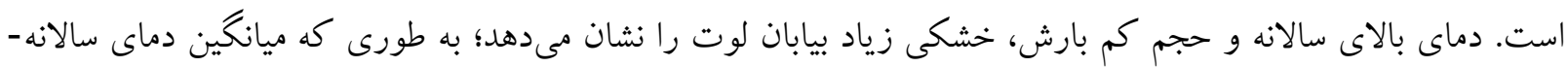

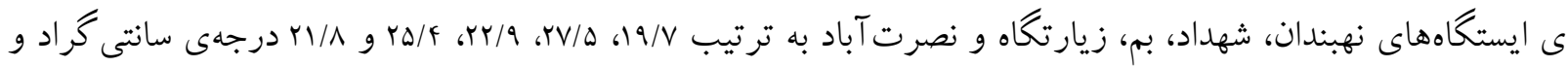

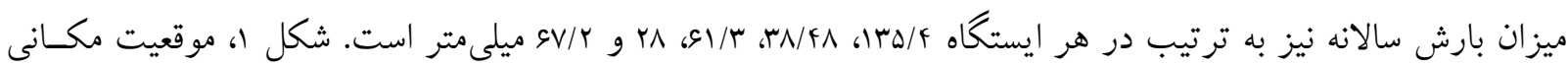
بيابان لوت را نشان مىدهد.

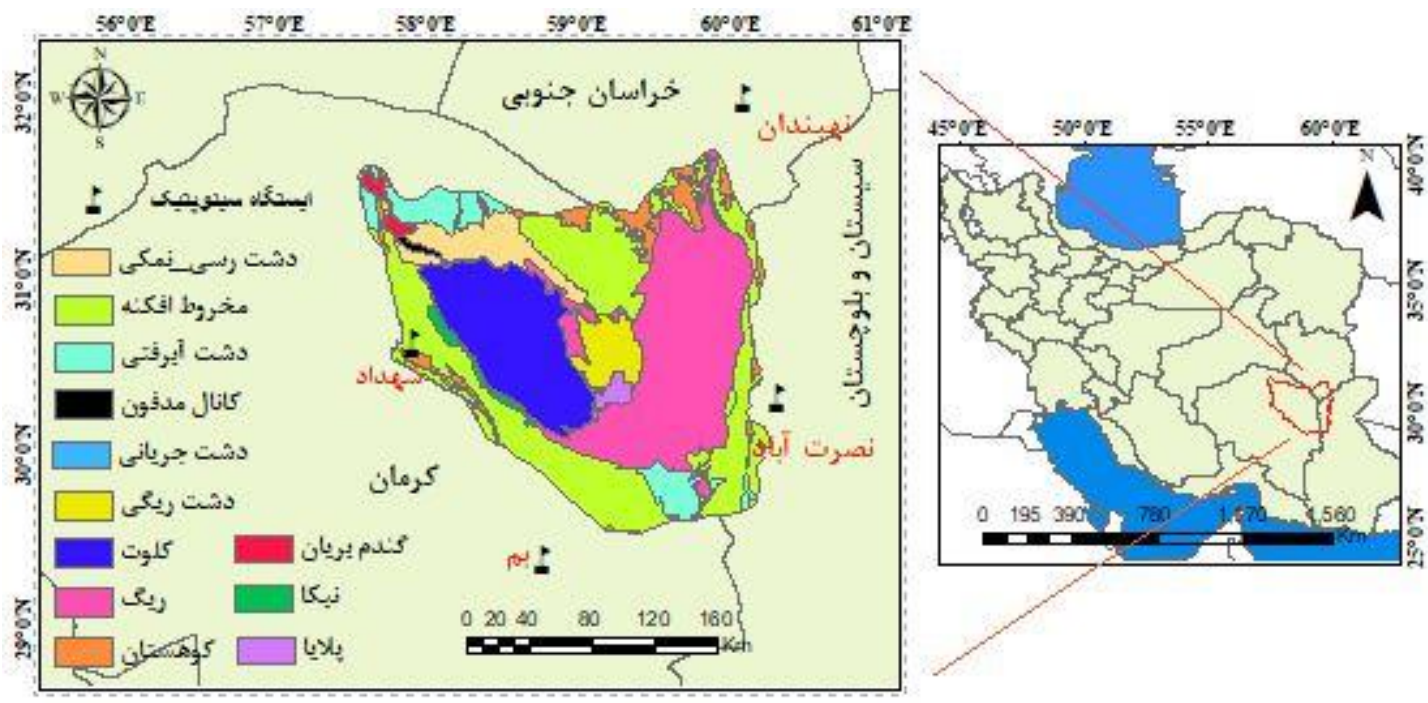

شكل ا: موقعيت جغرافيايى منطقهى مورد مطالعه

r- م مواد و روش

در اين يزوهش به منظور بررسى وضعيت باد و بررسى بادهاى فرساينده در سطح بيابان لوت، از دادههاى هواشناسى

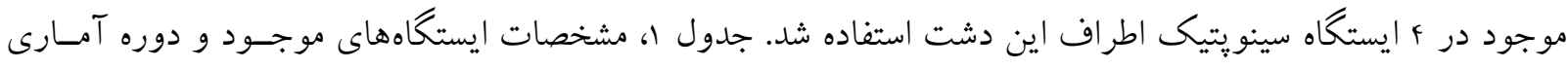

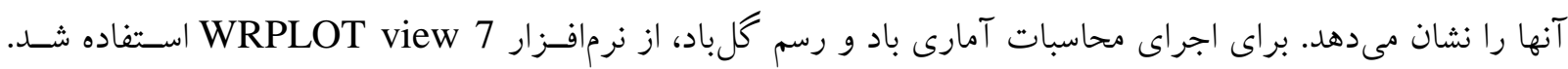

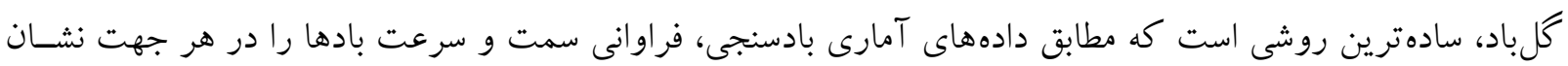


جدول ا: مشخصات ايستگاههاى سينو يتيك بيابان لوت

\begin{tabular}{|c|c|c|c|}
\hline ارتفاع (متر) & دوره آمارى & ايستگاه & رديف \\
\hline FAT & $r \cdot r-r \cdot 19$ & شهداد & 1 \\
\hline $1.9 \mathrm{~V}$ & $r \cdots-r \cdot 19$ & بم & r \\
\hline $11 M$ & $r \cdots-r .19$ & ن ن نهبندان & $r$ \\
\hline IITV & $r \cdot 1 r-r .19$ & نصرت آباد & f \\
\hline
\end{tabular}

همجنين به منظور ترسيم گلماسهى ايستگاههاى موجود در اطراف بيابان لوت، به دليل حجم بالاى محاسبات از نرم-

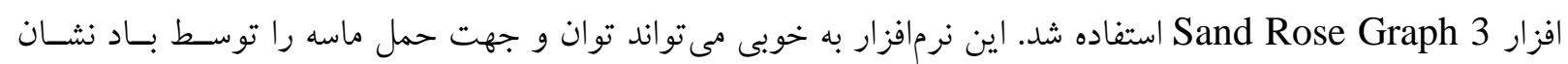

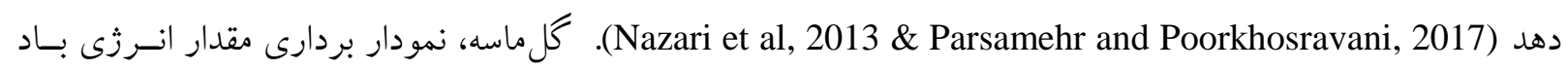
براى حمل ماسه است و توان فرسايشى باد و مقدار نسبى حمل ماسه رادر جهات مختلف نشان مىدهد. براى محاسـبهى مقادير يتانسيل حمل ماسه (DP) در جهات مختلف جغرافيايى، از رابطهى فراىبر كر و ديسن (Fryberger et al, 1979)

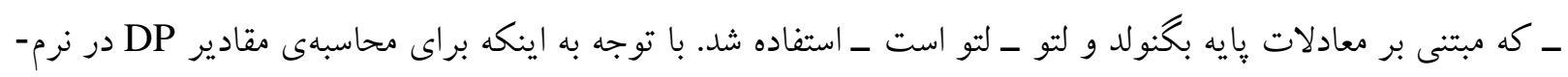

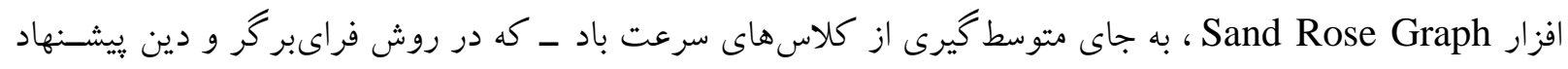

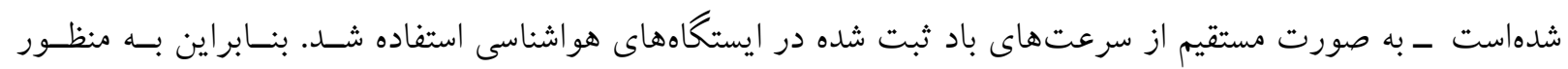

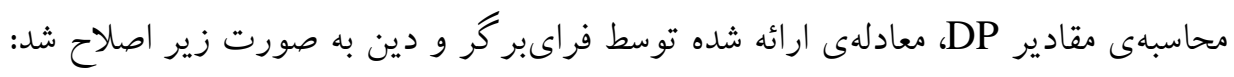

$$
D P=\frac{\sum v_{i j}^{2}\left(v_{i j}-V t\right)}{N} * T
$$

رابطهى 1

: سرعت بادهاى بيش از سرعت آستانه فرسايش در ساعات ديدبانى مختلف و در جهت جغرافيايى ز؛

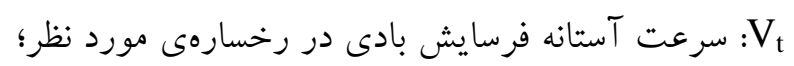

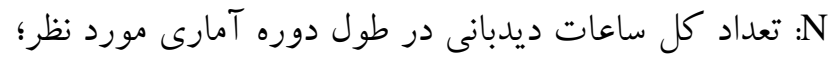
T

$$
T=\frac{n}{N}
$$

n : تعداد ساعات ديدبانى در مدت زمان مورد نظر (سالانه، فصلى و ماهانه)؛ N N تعداد كل ساعات ديدبانى در طول دوره آمارى مورد نظر. از مجموع مقادير DP در جهات مختلف، مجموع توان حمل ماسه (DPt) به دست مى آيد و در واقع، شاخصى اسـت

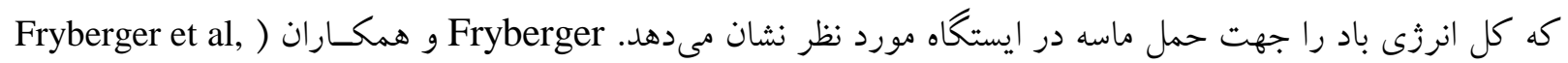
1979)، قدرت فرسايشى باد را بر اساس شاخص توان حمل باد طبق جدول r طبقهبندى كردند. 
جدول r r تقسيمبندى قدرت فرسايش باد در محيطهاى بيابانى (Fryberger et al, 1979)

\begin{tabular}{|c|c|c|}
\hline قدرت فرسايشى باد & مجموع توان حمل ماسه (DPt) & رديف \\
\hline 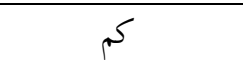 & $<r \ldots$ & 1 \\
\hline 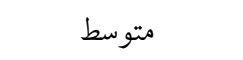 & $F \cdots-r \cdots$ & r \\
\hline 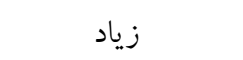 & $>f \cdots$ & r \\
\hline
\end{tabular}

DP بيانكر مقدار يا اندازهى بردار بر آيند (بردار منتجه) توان حمل ماسه است كه از جمع بـردارى مقــادير :RDP' در جهات مختلف ^ يا عا كانه حاصل مىشود و وضعيت نهايى حمل ماسه را در منطقهى مورد مطالعه نشان مىدهد.

$$
\begin{array}{ll}
R D P=\sqrt{\left(C^{2}+D^{2}\right.} & \text { رابطهى رابطهى } \\
C=\sum \text { (DPi) } \sin \theta i & ه \text { رابطهى }
\end{array}
$$

$$
\text { O: - زاويهى جهت حمل ماسه (جهت باد)؛ }
$$$$
\text { DP توان حمل ماسه؛ :DP }
$$

: جهت خالص حركت ماسه (جهت بردار منتجه) را در طول سال، ماه يا فصل مورد نظر نشان مسىدهـد و بــا. استفاده از رابطهى زير به دست مى آيد:

$$
\text { RDD = Arc tan (C/D) }
$$

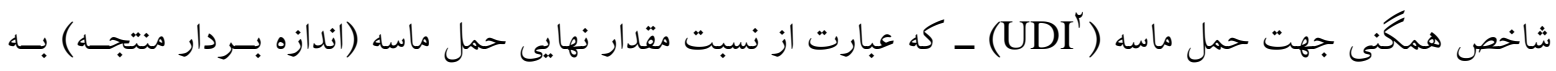

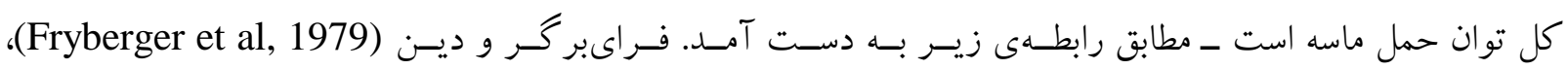

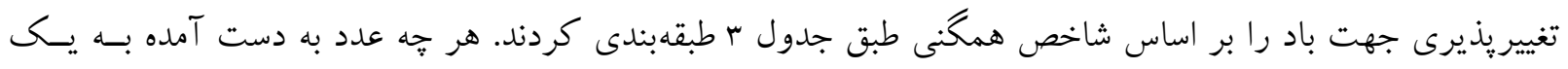

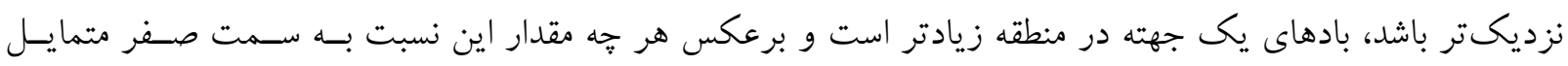
باشد، بادهاى قدرتمند جندجهتى بر منطقه حاكم است.

$$
\text { UDI = RDP / DPt }
$$

\footnotetext{
${ }^{1}$ Resultant Drift Potential

${ }^{2}$ UniDirectional Index
} 
جدول r: تقسيمبندى شاخص تغيير يذيرى جهات باد (Fryberger et al, 1979)

\begin{tabular}{|c|c|c|c|}
\hline طبقهبندى جهات باد & قدرت فرسايشى باد & شاخص همخنى جهت باد (UDI) & رديف \\
\hline بادهاى يك جهته & كم & $>\cdot / \Lambda$ & 1 \\
\hline بادهاى دو جهته با زاويهى منفرجه & متوسط & $\cdot / \mu-\cdot / \Lambda$ & r \\
\hline بادهاى جֶند جهته مر كب با زاويهى تند & زياد - اد & $<\cdot / \mu$ & r \\
\hline
\end{tabular}

به منظور تعيين مقدار ماسهى منتقل شده در واحد زمان، از يكى واحد عرض از معادلات ارائه شــده توسـط بكنولــد،

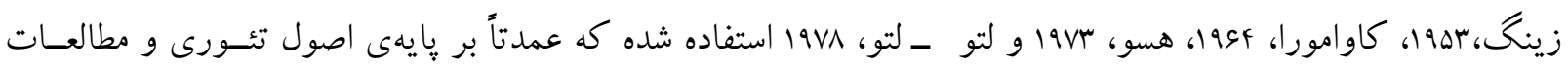

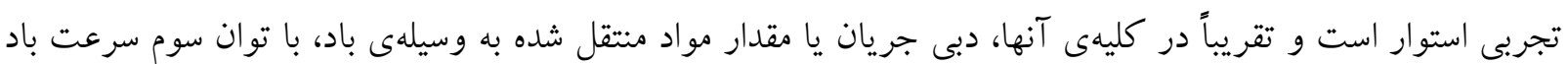
متناسب است و بر اساس وزن مواد منتقله در واحد عرض در واحد زمان بيان مىشود. در اين تحقيق، قطر متوسط ذرات

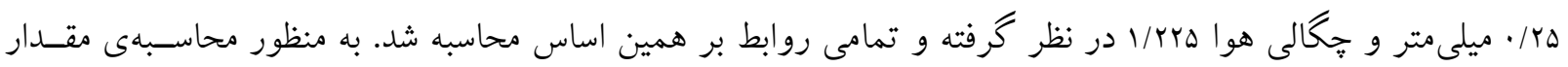

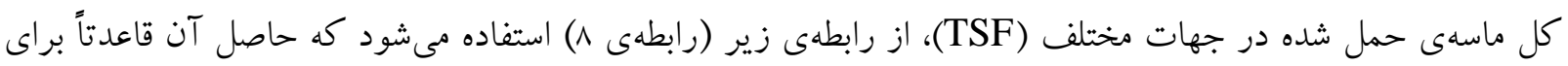
هر يك از روابط استفاده شده در بالا متفاوت است:

$$
T S F=Q * \mathrm{~T}
$$

رابطهى 1

: مقدار دبى ماسه محاسبه شده با استفاده از هر يك از روابط؛ T: طول دورهى زمانى (سال، فصل، ماه) كه براساس تعداد ساعات ديدهبانى در طول روز محاسبه مى شود.

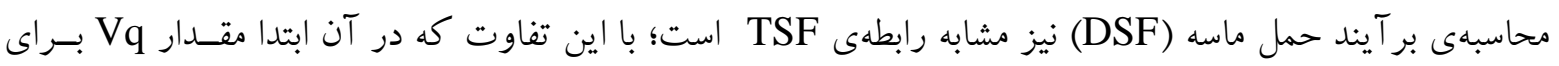

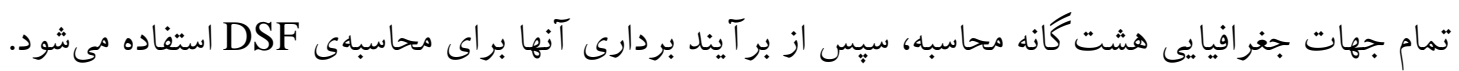

\section{F}

در شكل rا، كلبادهاى ايستخاههاى سينو يتيك واقع در اطر اف بيابان لوت به صورت سالانه نمـايش داده شــدهاسـت.

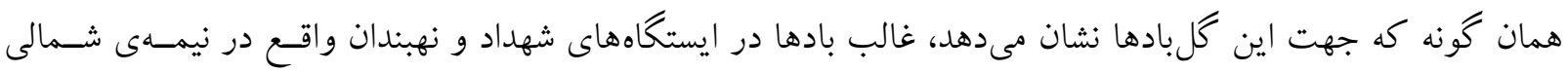

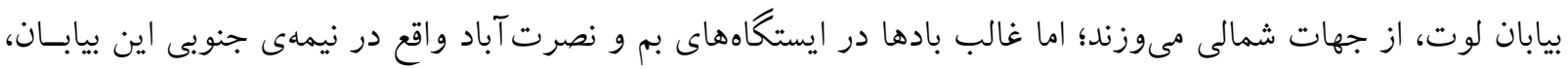

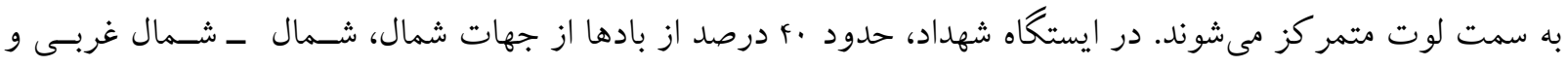

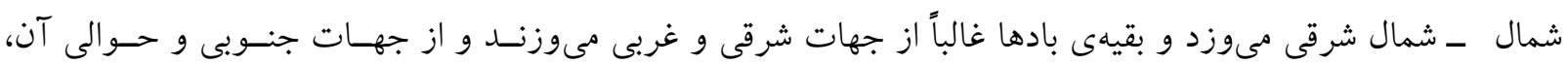

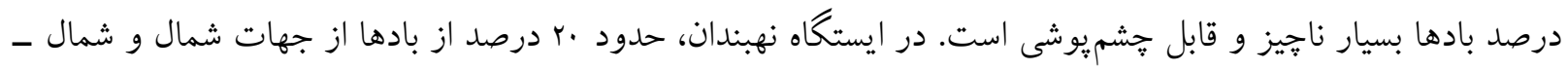

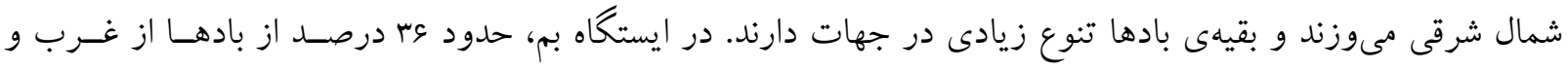

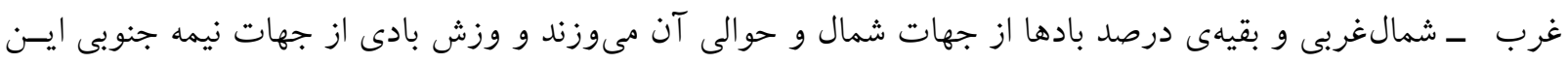

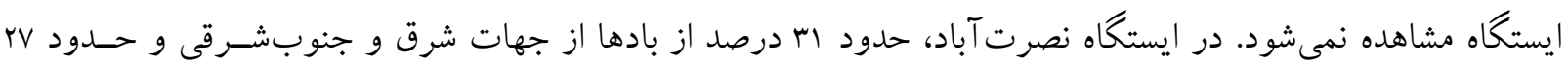
درصد از جهات غرب و شمالغربى و بقيهى بادها از ساير جهات با تنوع زياد مىوزند. 


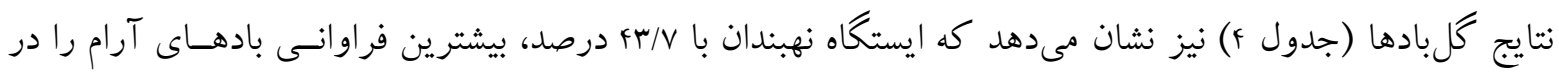

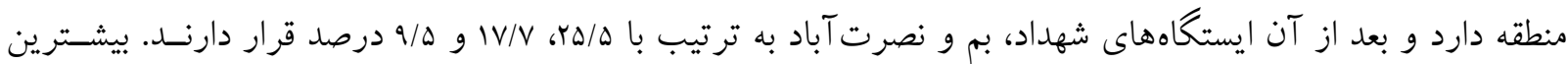

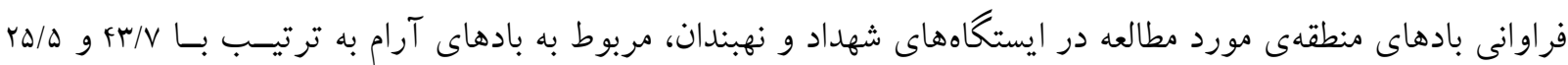

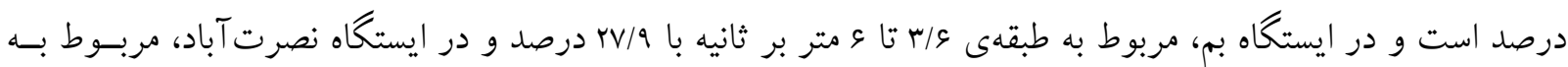

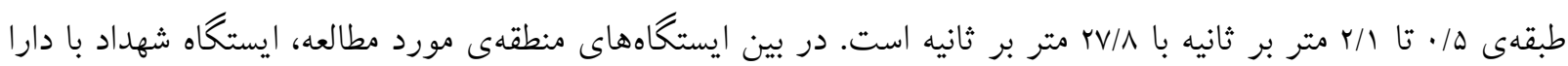

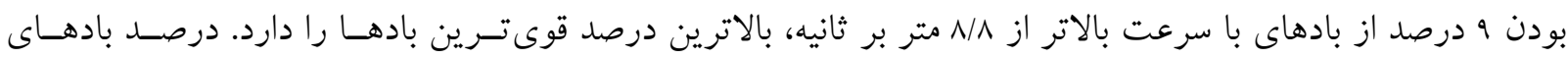

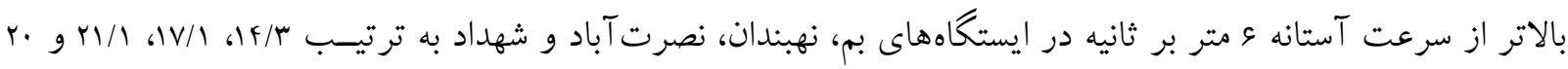

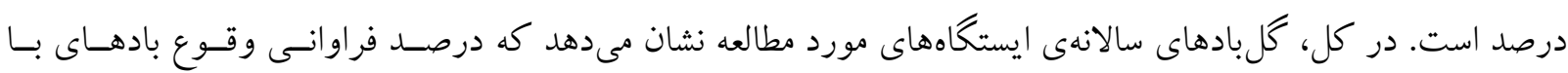

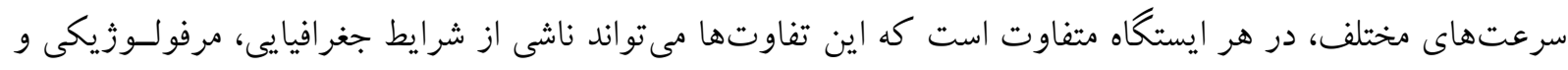
بادناكى هر منطقه باشد. شكل ب نيز بالاترين سرعت باد ثبت شده در هر ماه را براى كليهى ايستكاههاى بادسنجى نشـان

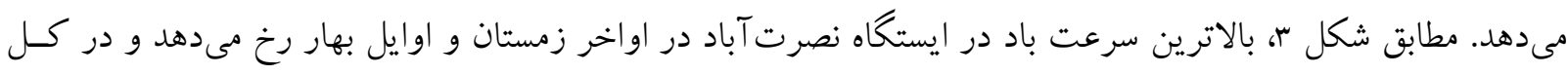
نسبت به ساير ايستخاهها، كمترين سرعت بادهاى ثبت شده در سال را دارد. در ايستخاههـاى شـهداد و بــم، بـالاترين

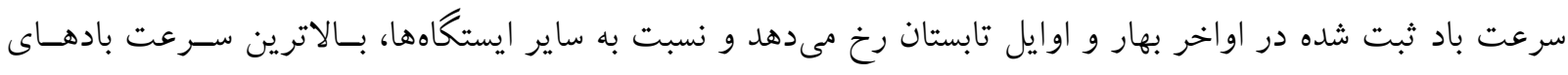

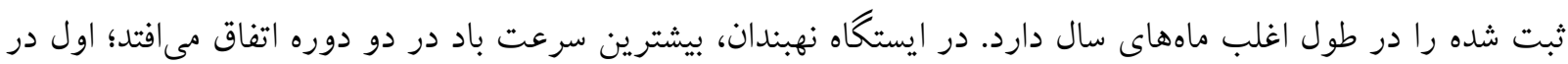
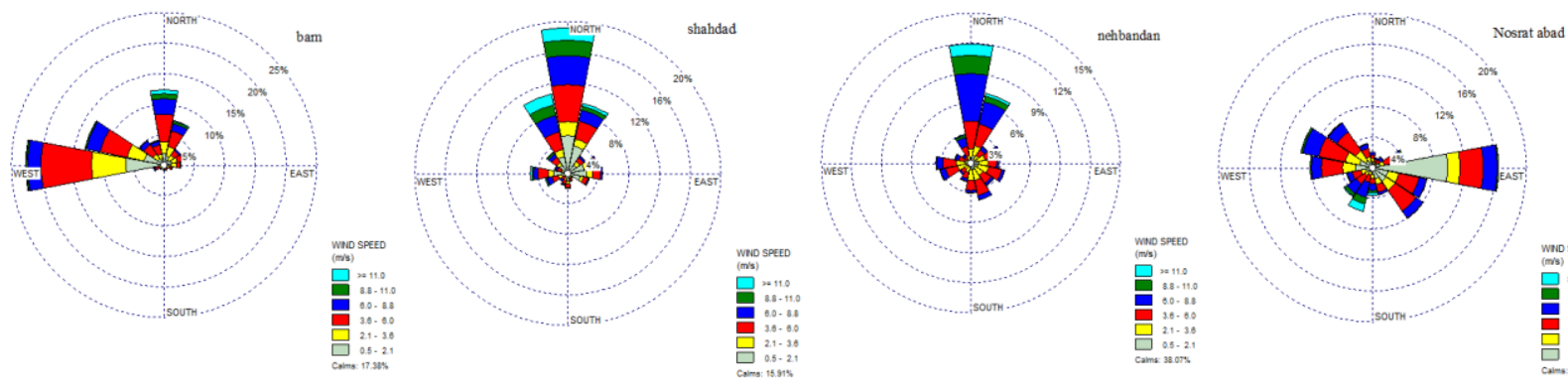

اوايل بهار و دوم در بـين

ماههاى اواخر تابستان و اوايل پياييز.

شكل ץ: گل بادهاى سالانهى ايستكاههاى سينو يتيك منطقهى مورد مطالعه

جدول f: درصد وقوع طبقات سرعت باد ايستخاههاى منطقهى مورد مطالعه

\begin{tabular}{|c|c|c|c|c|c|c|c|}
\hline \multicolumn{7}{|c|}{ درصد وقوع طبقات سرعت باد } & \multirow[t]{2}{*}{ ايستگاه } \\
\hline$>11$ & $\|-\Lambda / \Lambda$ & $\Lambda / \Lambda-\varsigma$ & $\varepsilon-r / s$ & $r / s-r / l$ & $r / l-\cdot / \Delta$ & آرام & \\
\hline $1 / r$ & r & $11 / 1$ & $r V / q$ & $11 / 1$ & $r Y / r$ & IV/V & بم \\
\hline$F / r$ & $\mathrm{~F} / \mathrm{A}$ & $1 \cdot / 9$ & $M / Y$ & $9 / r$ & $r V / l$ & $r \Delta / \Delta$ & شهداد \\
\hline $1 / V$ & r & $1 Y / F$ & $1 \wedge / 1$ & $\mid r / r$ & $\Lambda / \Lambda$ & $\mathrm{Fr} / \mathrm{V}$ & 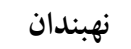 \\
\hline $1 / 8$ & $r / V$ & $1 \varepsilon / 1$ & $r \varepsilon / 9$ & $\mid f / \Lambda$ & $r V / \Lambda$ & $9 / \Delta$ & نصرت آباد \\
\hline
\end{tabular}




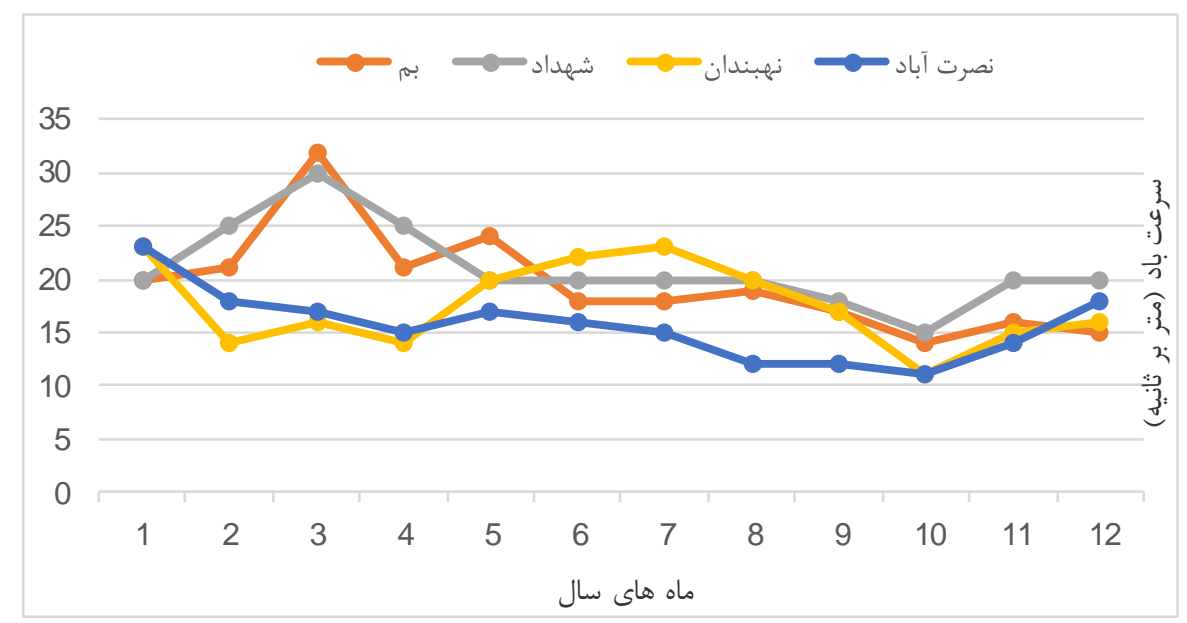

شكل ץ: نمودار بالاترين سرعت باد در هر ماه براى ايستگاههاى بيابان لوت

نتايج تحليل كل بادهاى ايستكاههاى منطقهى مورد مطالعه براى فصول سال نشان مىدهد كه در ايستگاه بم (شكل F)، بادهاى غربى با درصد وقوع حدود ·r تا هr درصد، در كليهى فصول غالب هستند و ساير بادها از جهات شمالى و مابين غربى ــ شمال شرقى مىوزند. در فصل تابستان علاوه بر جهت غربى، بادهاى با جهت شمالى با حسـود سا درصــ نيـز غالب هستند. در ايستگاه نهبندان (شكل ه) در فصل بهار و تابستان، غالب بادهاى اين ايستخاه از جهات شمالى و و شمال

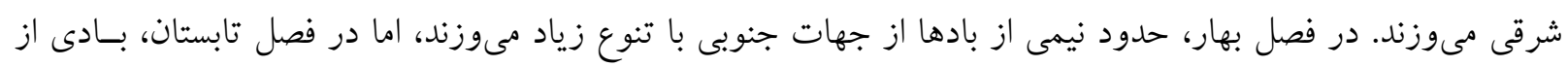

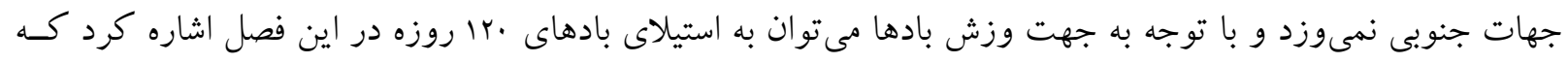

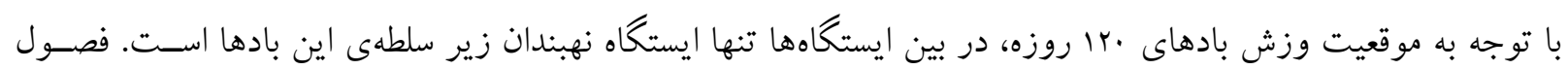

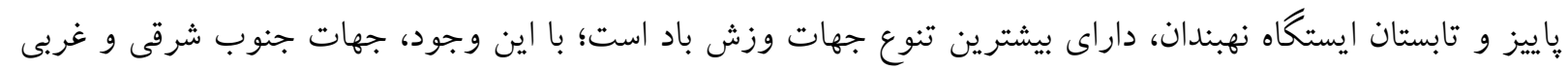

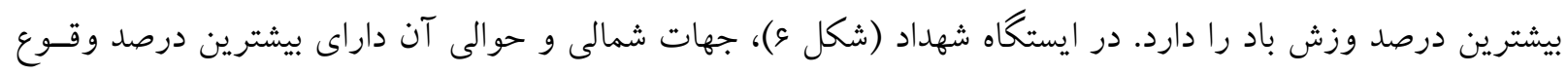

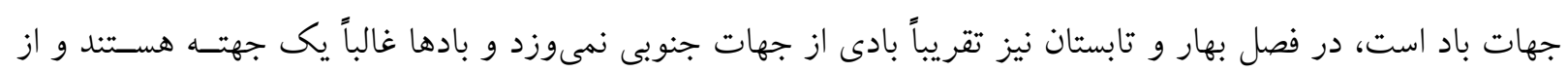

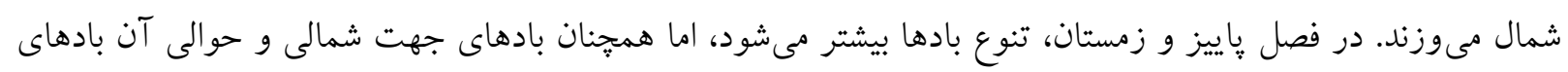

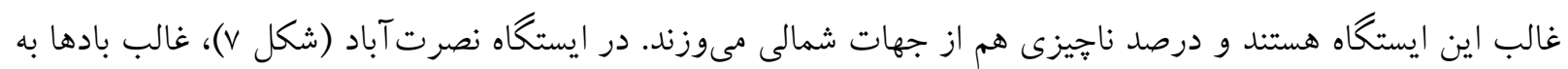

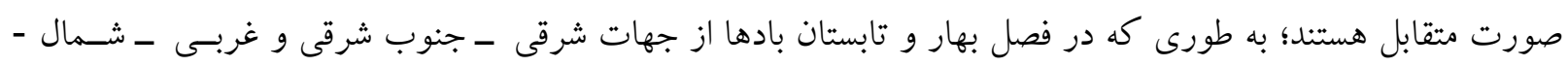

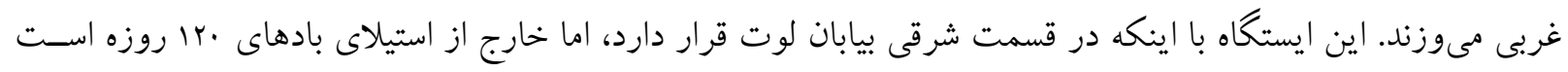

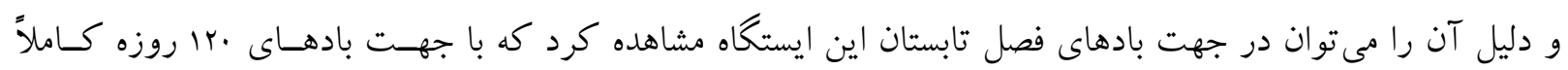
متفاوت است. در فصل زياييز علاوه بر جهات شرقى - جنوب شرقى و غربى ـ شمالغربى، باد غالـب از جهـت شـرقى

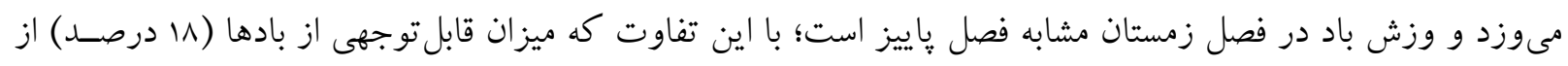
جهات جنوب شرقى و اطراف آن مىوزد. 

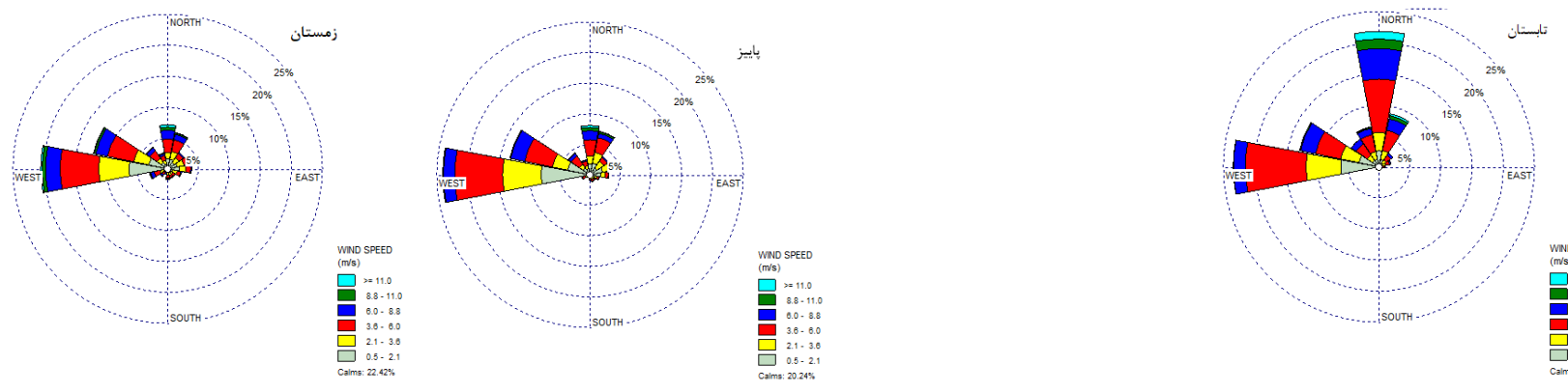

شكل \&: كلبادهاى فصول سال در ايستكاه بم
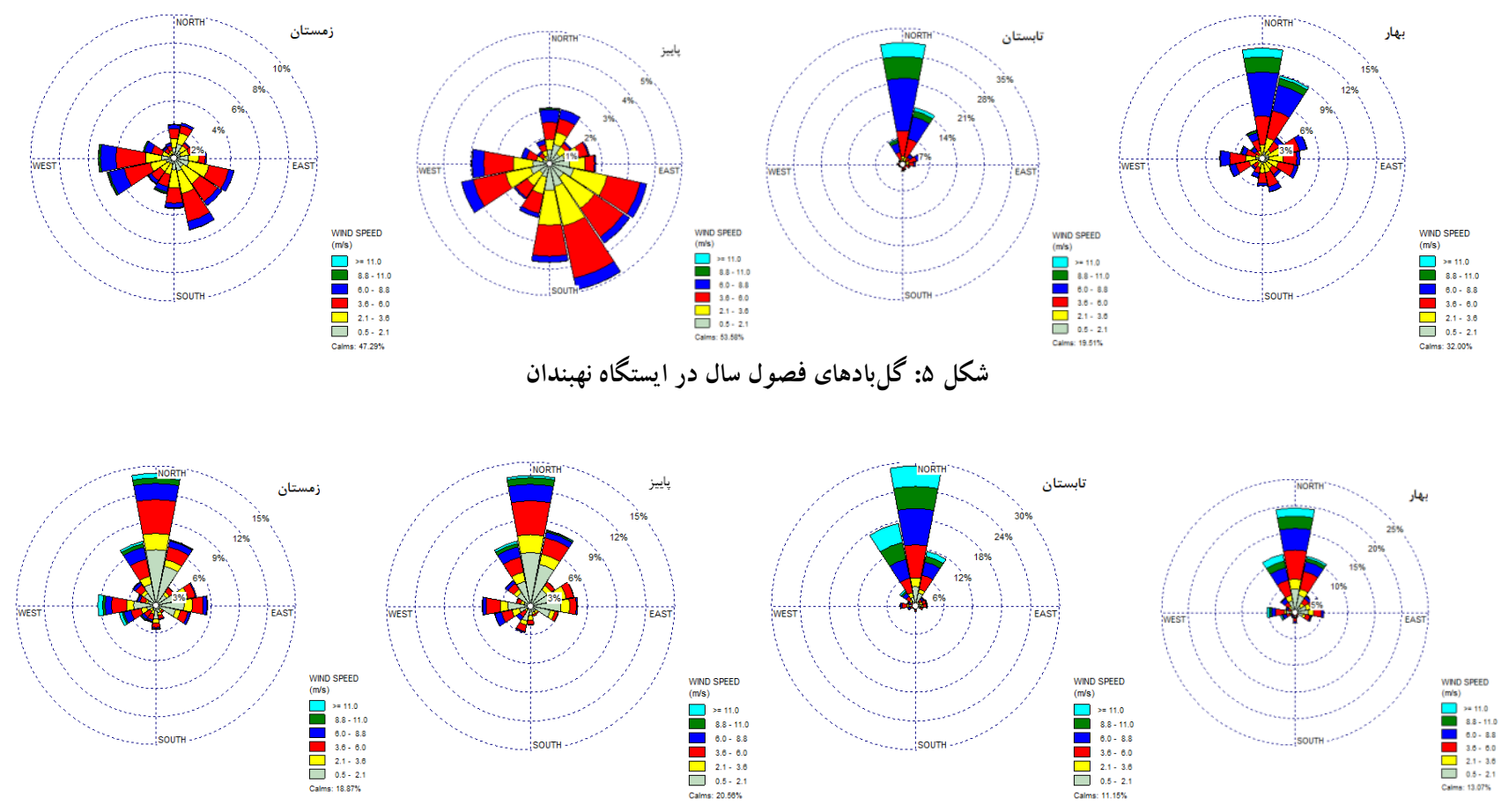

شكل \&: گلبادهاى فصول سال در ايستخاه شهداد
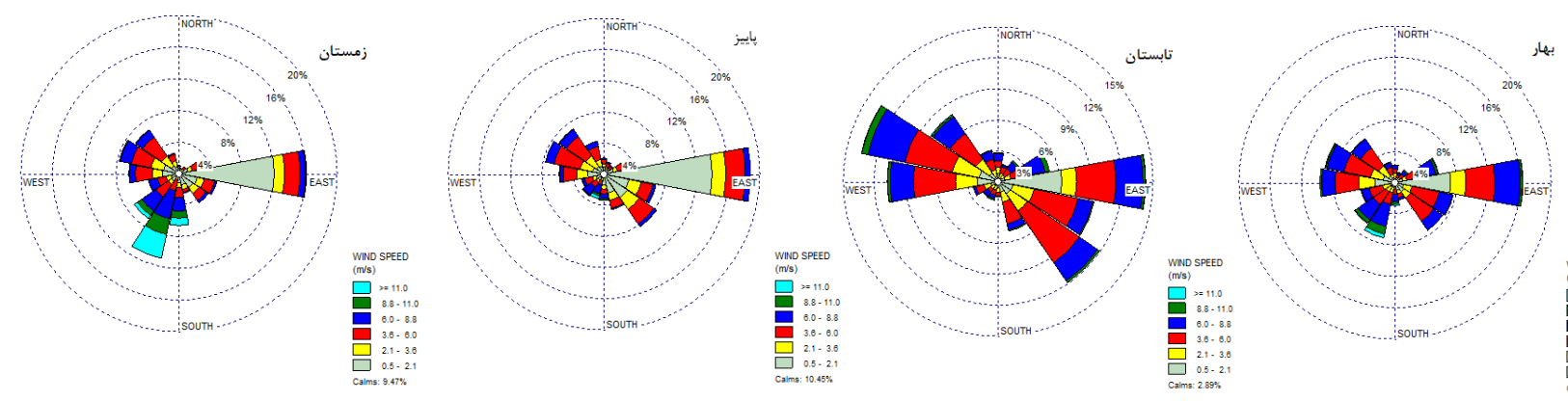

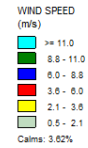

شكل V: گل بادهاى فصول سال در ايستگاه نصرت آباد 
به منظور بررسى طوفانخيزى بيابان لوت و مطالعهى بادهاى فرسايندهى آن، كلطوفانهاى ايستخاههاى مورد مطالعه

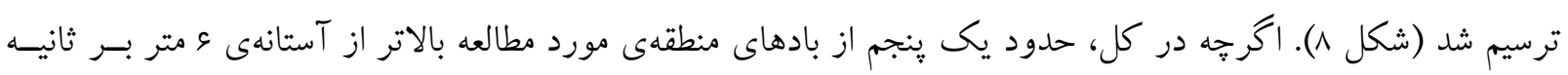

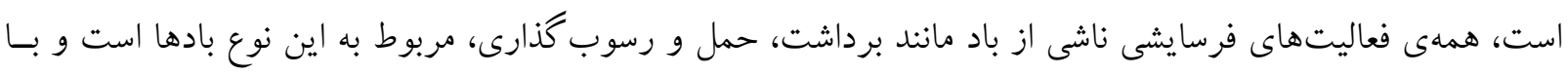
توجه به حاكميت شرايط اقليمى خشك، هموارى سطح زمين، رطوبت اندك خاكى و وجود ذرات ريزدانه در سطح، مى -

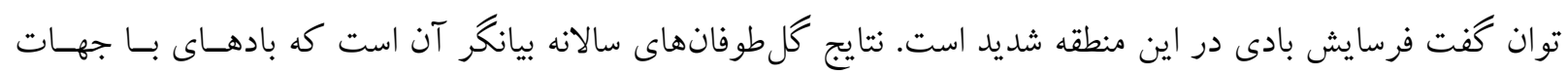

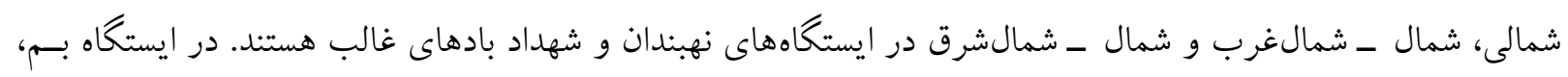

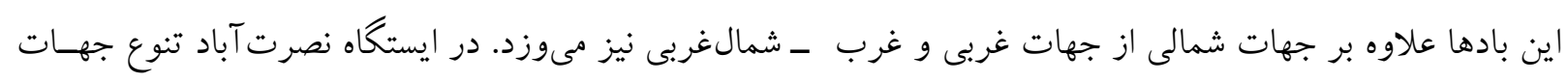

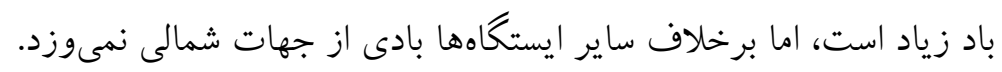
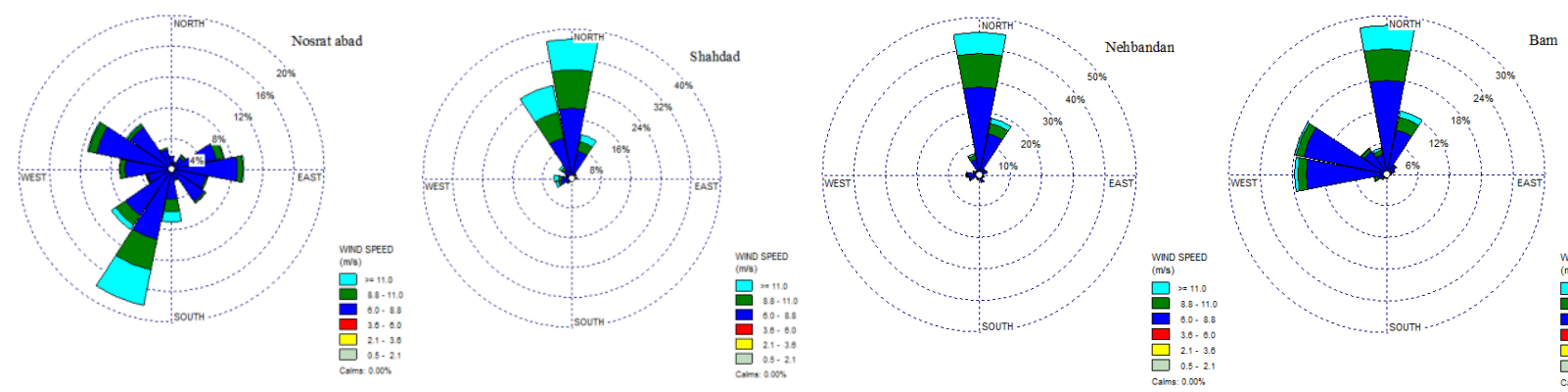

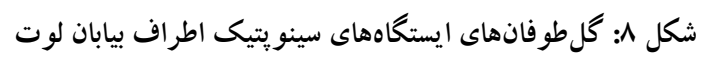

مطابق شكل 9، حدود ·f درصد از بادهاى فصل تابستان ايستكاههاى شهداد و نهبندان، بالاتر از سـرعت آسـتانه رخ

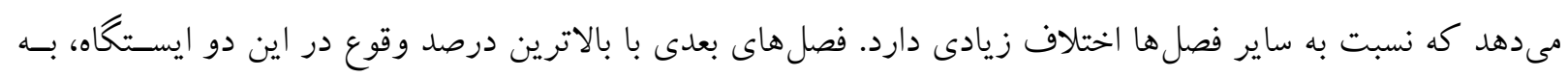

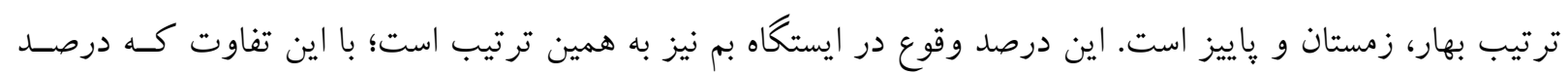

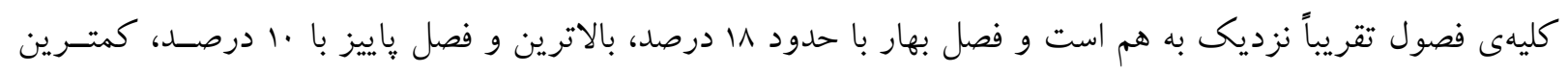

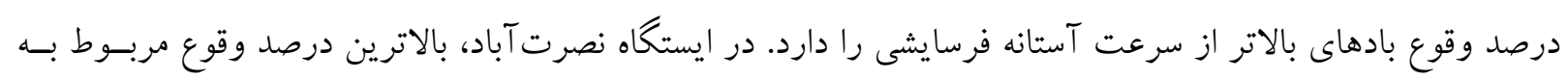

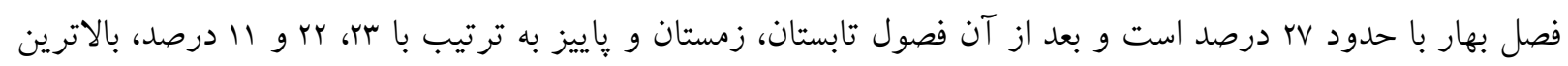
درصد وقوع بادهاى بالاتر از سرعت آستانه فرسايشى را دارد. 


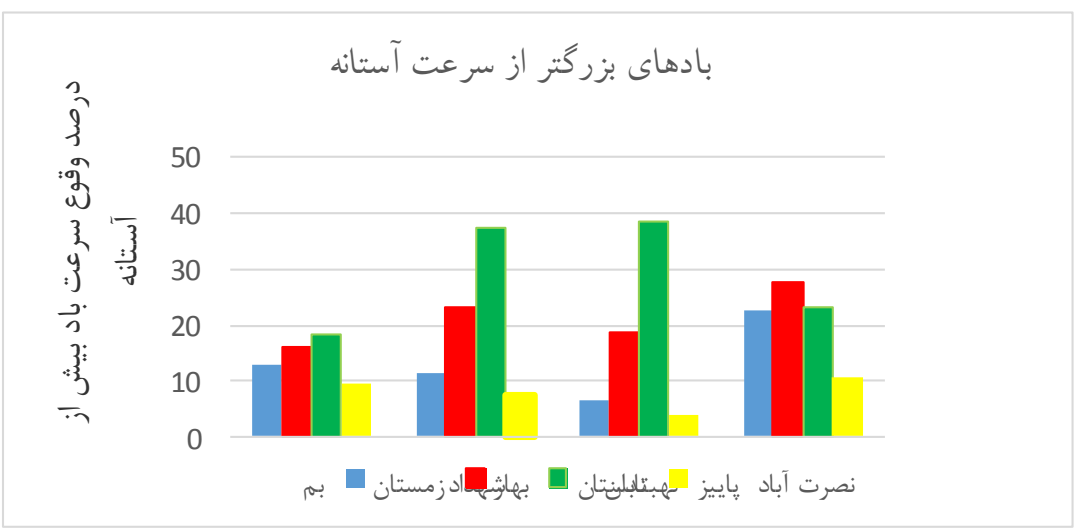

شكل 9: نمودار درصد وقوع بادهاى بالاتر از سرعت آستانه فرسايشى در هر فصل

در شكل •ا، كل ماسههاى سالانهى مربوط به ايستخاههاى سينويتيك بيابان لوت مشاهده مىشود و اطلاعات مربوط به تحليل كلماسهها نيز در جدول ه ذكر شدهاست. تحليل جهت خالص حركت ماسهى (RDD) ايستخاههاى مورد مطالعه

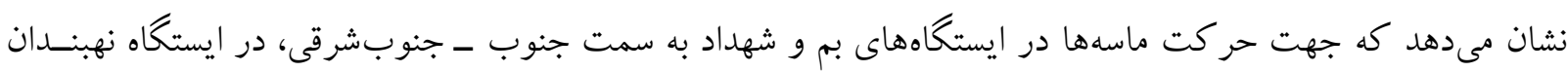

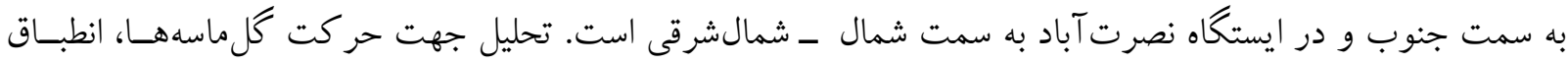

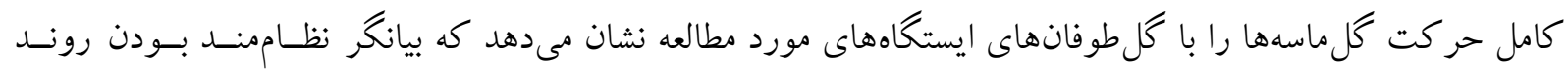

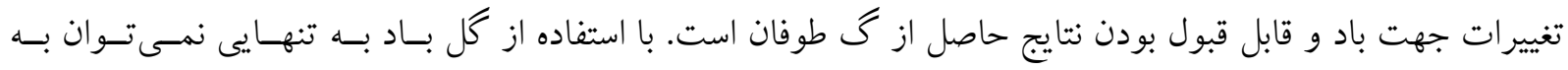

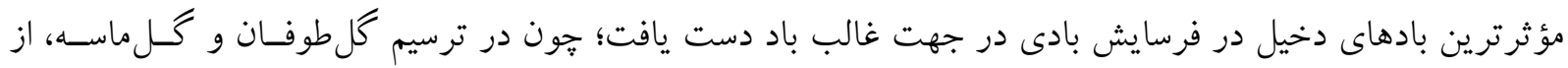

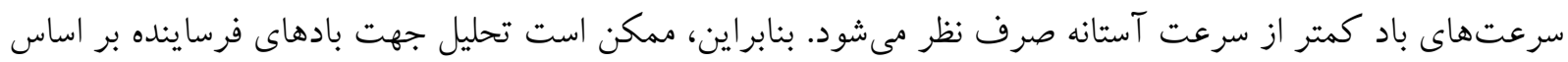

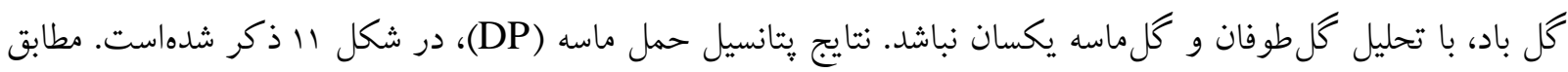

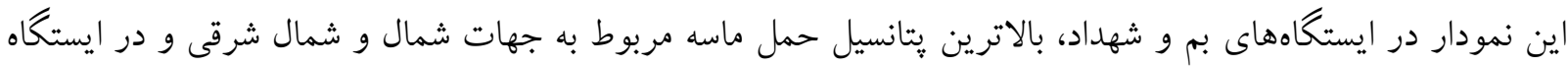

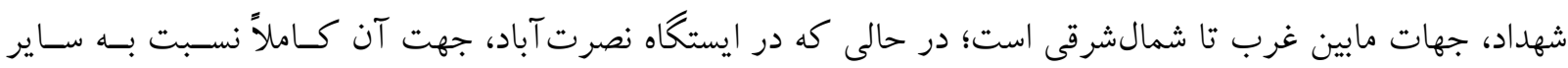

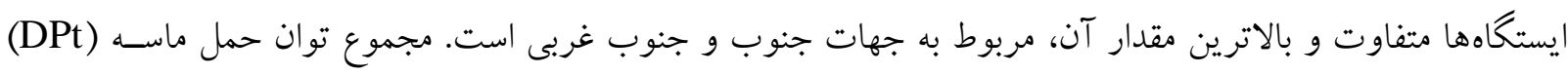

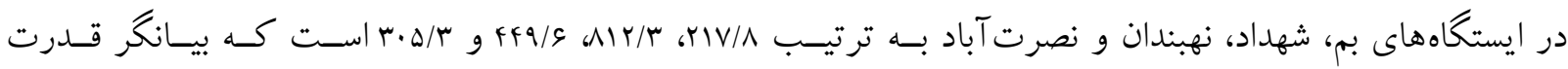

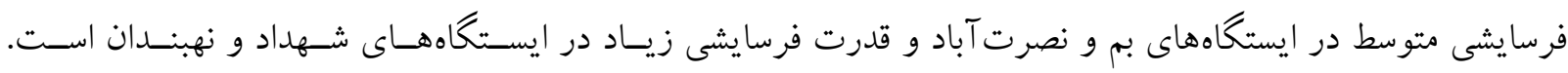

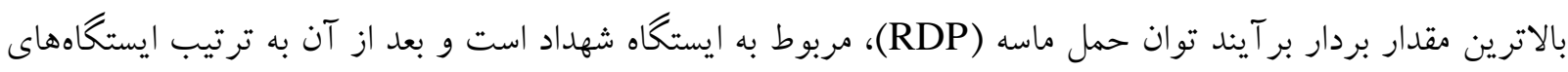

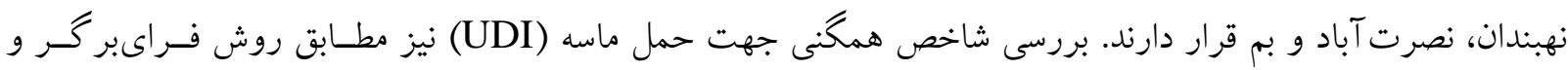

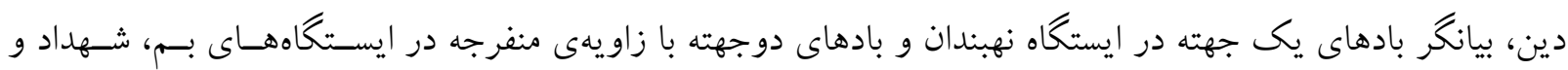



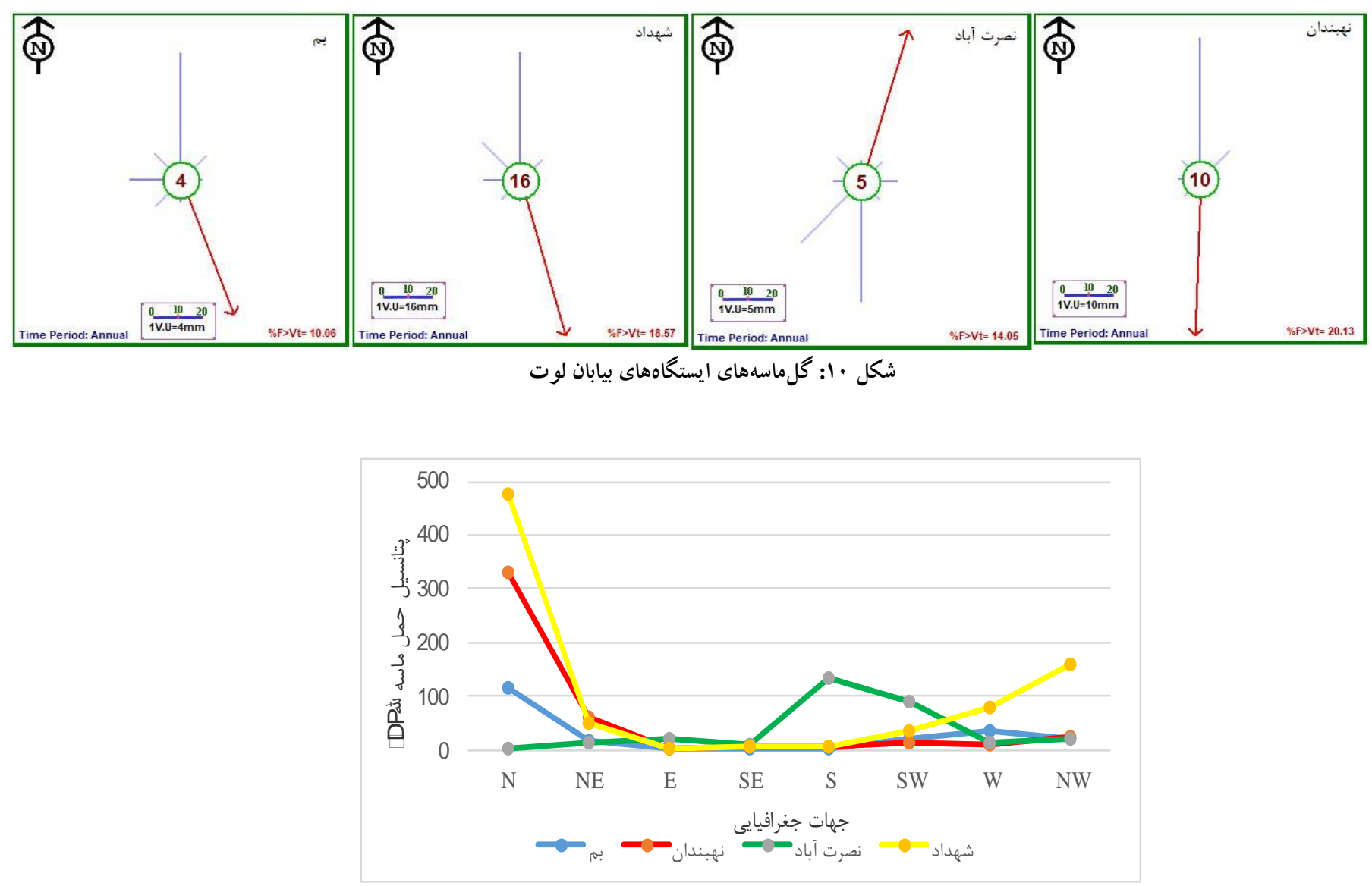

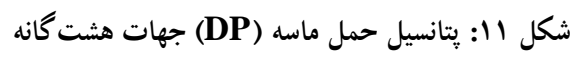

جدول ه: نتايج گلماسههاى ايستخاههاى بيابان لوت

\begin{tabular}{|c|c|c|c|c|}
\hline UDI & RDD & RDP & DPt & ايستگًاه \\
\hline . $|A T|$ & 109 & $140 / 194$ & TIV/A & بم \\
\hline$\cdot / V \Delta V$ & 194 & g/f/qsf & $1 / r / r$ & شهداد \\
\hline • & INT & TVT/TYG & $p \& q / 9$ & نهبندان \\
\hline$\cdot 19 \cdot V$ & IV & $\mid \wedge \Delta / T F \Lambda$ & $r \cdot \Delta / r$ & نصرت آباد \\
\hline
\end{tabular}

نتايج حاصل از تحليل گلماسه، در قالب مجموع يتانسيل حمل ماسه (DPt) و شاخص همخنى جهـت حمـل ماســ

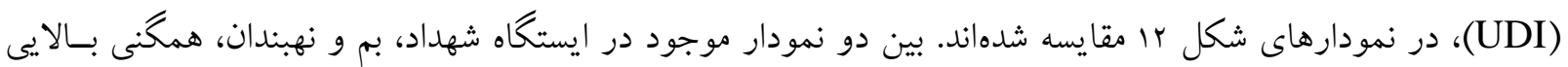
وجود دارد؛ به طورى كه هر زمان شاخص UDI نزديك به يك باشد و باد نيز يك جهته باشد، شـاخص تـوان حمـل

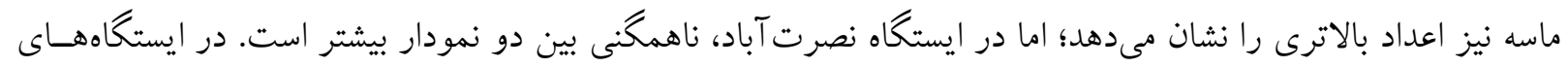
شهداد، بم و نهبندان، بيشترين مقدار بادهاى يك جهته در فصل پاييز رخ مىدهد كه در همين زمان بـالاترين پّانسـيل

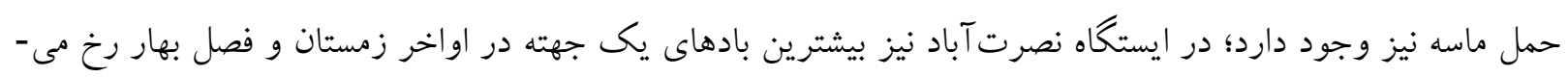
دهد و بالاترين يتانسيل حمل ماسه نيز در فصل بهار. 

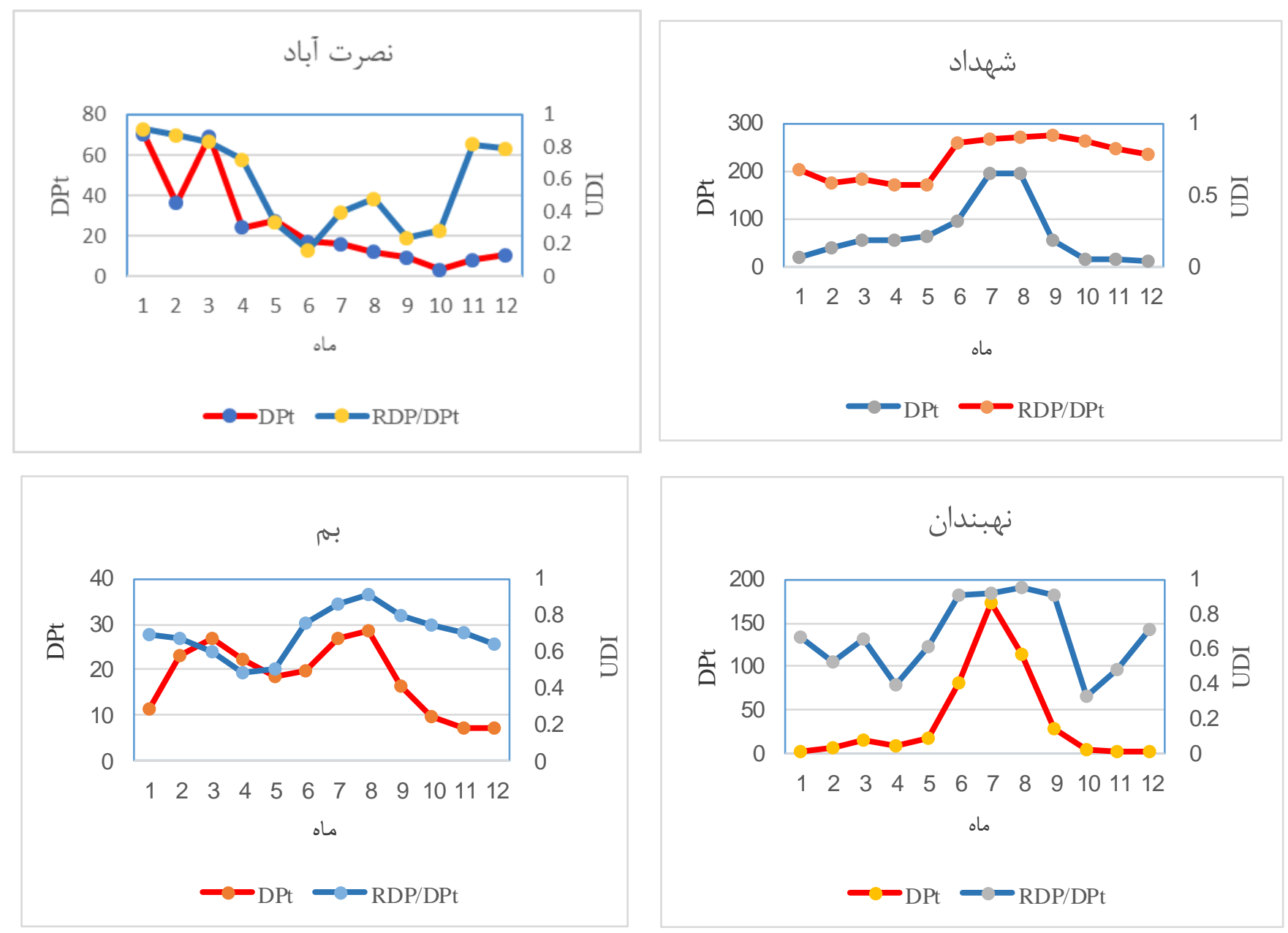

شكل r ا: مقايسهى نتايج مجموع يتانسيل حمل ماسه (DPt) و شاخص همكنى جهت حمل ماسه (UDI)

نتايج حاصل از دبى حمل ماسه (Qs) در جدول ع، نشان مىدهد كه در ايستگاه بم، بيشترين مقدار دبى حمـل ماسـه

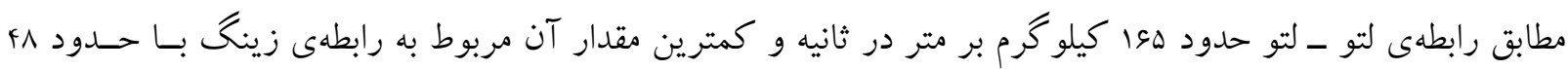

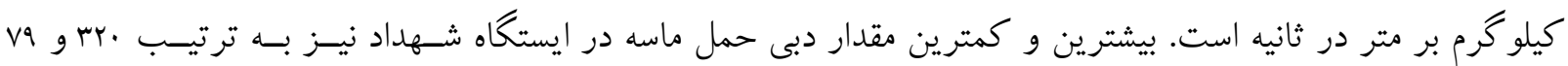

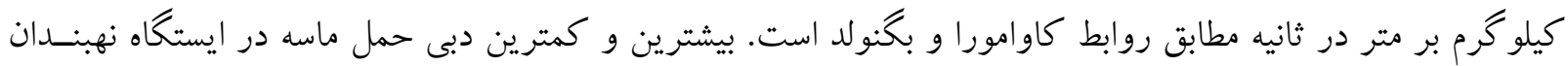

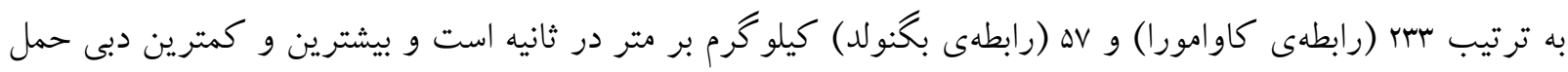
ماسه در ايستخاه نصرت آباد به ترتيب r.r (رابطهى كاوامورا) و •ه (رابطهى بكنولد) كيلو گرم بر متر در ثانيه است. 
جدول \&: مقدار دبى ماسه حمل شده (Qs) براى هر رابطه

\begin{tabular}{|c|c|c|c|c|c|}
\hline \multicolumn{5}{|c|}{ دبى حمل ماسه (Kg/m.s) Qs) } & \multirow[b]{2}{*}{ ايستگاه } \\
\hline لتو و لتو (19マ^) & هسو (19VY) & كاوامورا (199F) & زينت (سهو) & بََنولد (9FI) & \\
\hline $194 / 99$ & $1 T / 1 T$ & $|\wedge V / T|$ & $F V / V T$ & GI/Tr & بم \\
\hline$\mu \cdot \mu / I f$ & $\mid F \cdot / \Lambda F$ & mr. & $\Lambda I / \Lambda F$ & VN/M & شهداد \\
\hline$r \cdot \Delta / s q$ & $1 \cdot Y / Y \mu$ & וT/M & $\Delta q / F$ & $\Delta V / T G$ & نهبندان \\
\hline $1 V 9 / 1 T$ & $\Lambda \Lambda / \Lambda V$ & $r \cdot r / r F$ & $\Delta 1 / s F$ & $\mathrm{Fq} / \mathrm{vN}$ & نصرت آباد \\
\hline
\end{tabular}

در جدول V، مقدار ماسهى حملشده (TSF) و بر آيند حمل ماسه (DSF) مطابق روابط بخنولد، زينگ، كاوامورا، هسو و

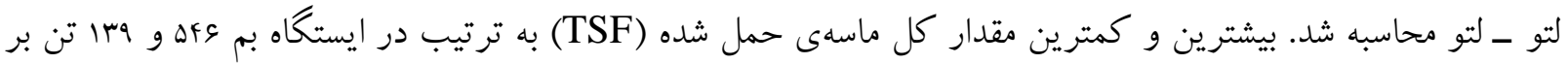

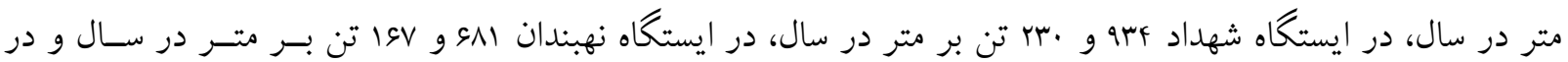

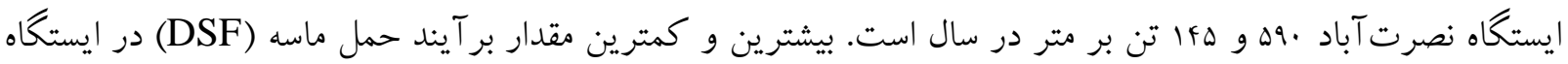

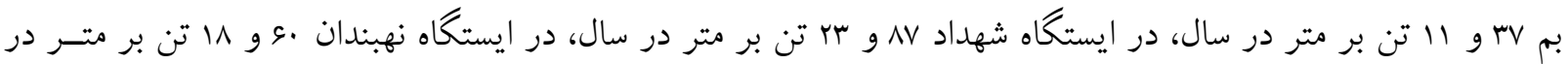

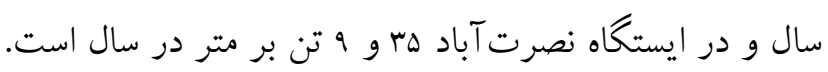
جدول V: مقدار ماسه حمل شده (TSF) و بر آيند حمل ماسه (DSF) مطابق روابط استفاده شده

\begin{tabular}{|c|c|c|c|c|c|c|c|c|}
\hline \multicolumn{2}{|c|}{ نصرت آباد } & \multicolumn{2}{|c|}{ نهبندان } & \multicolumn{2}{|c|}{ شهداد } & \multicolumn{2}{|c|}{ بم } & \multirow{2}{*}{ روابستكاه } \\
\hline DSF & TSF & DSF & TSF & DSF & TSF & $\begin{array}{c}\text { DSF } \\
\text { (ton/m.year) }\end{array}$ & $\begin{array}{c}\text { TSF } \\
\text { (ton/m.year) }\end{array}$ & \\
\hline 9 & $1 f \Delta$ & 11 & $I S V$ & r & r. & 10 & 189 & بكنولد \\
\hline 1. & 10 & 11 & IVT & YF & ז & 11 & 1149 & زينگ \\
\hline ra & 09. & g. & $9 \wedge 1$ & $\Lambda \mathrm{V}$ & $q \mu F$ & rV & DFG & كاوامورا \\
\hline IV & rDq & rr & rq1 & FY & $F 11$ & $r$. & rmq & هسو \\
\hline KF & QYT & щ & s.. & 09 & $\wedge \wedge \Delta$ & rr & $F \wedge 1$ & لتو و لتو \\
\hline
\end{tabular}

ه - بحث و نتيجل كيرى

در اين يزوهش، سرعت و جهت بادهاى فرساينده و توان و جهت حمل ذرات رسوب ناشسى از فرسـايش بـادى در

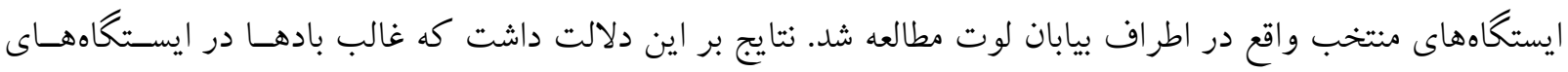

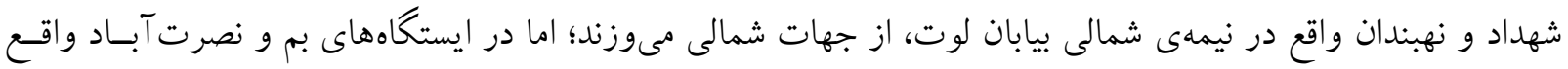
در نيمهى جنوبى اين بيابان، به سمت لوت متمر كز مىشوند. در كل، حدود يكى پِنجم از بادهاى منطقهى مــورد مطالعـه

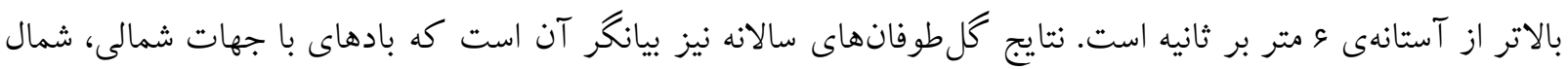

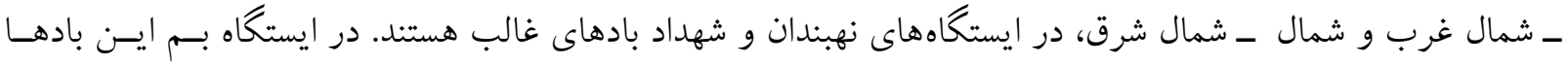

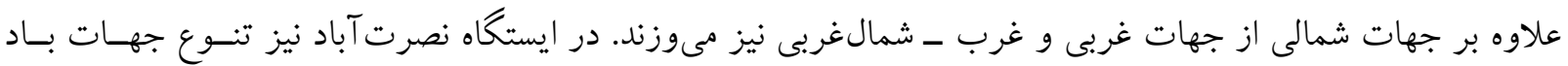


زياد است، اما برخلاف ساير ايستگاهها، بادى از جهات شمالى نمىوزد. بالاترين درصد وقوع بادهاى بـالاتر از سـرعت

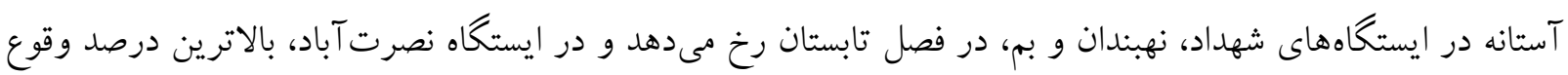
مربوط به فصل بهار است. تحليل جهت خالص حركت ماسه (RDD) نشان مىدهد كـه جهـت حركـت ماسـهـهـا در

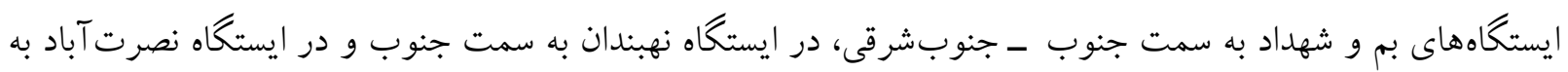

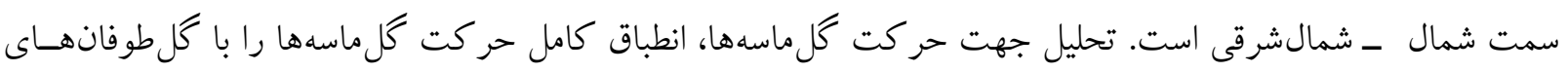

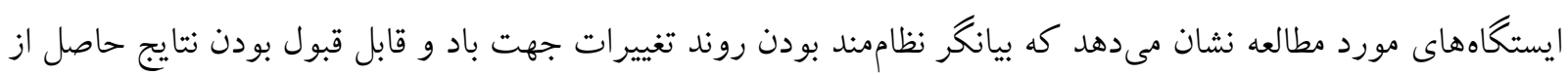

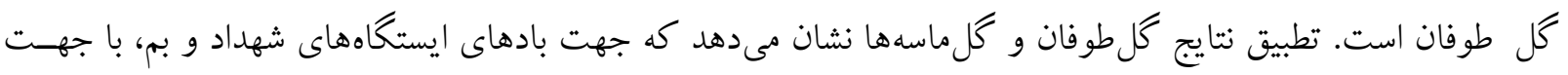

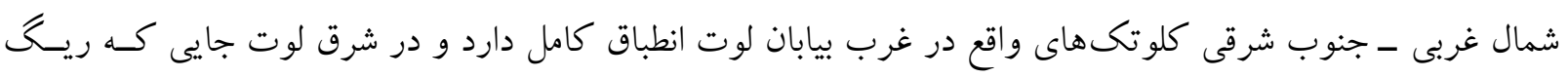

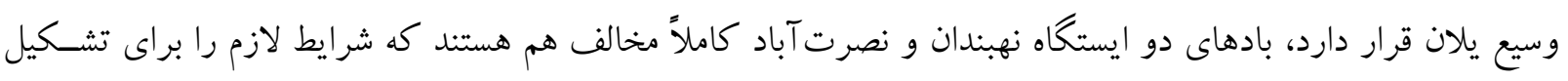

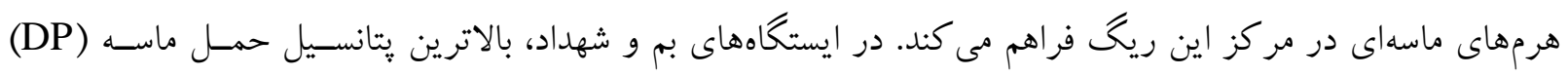

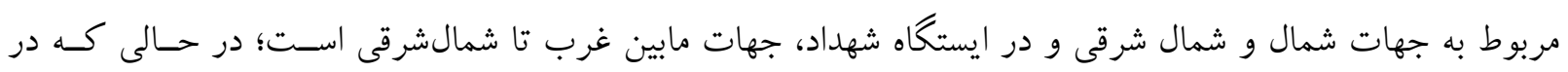

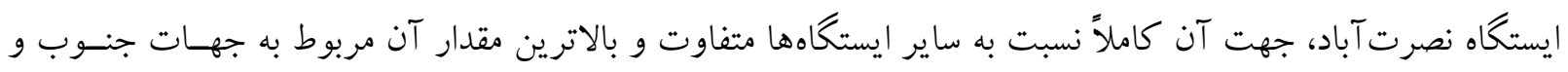

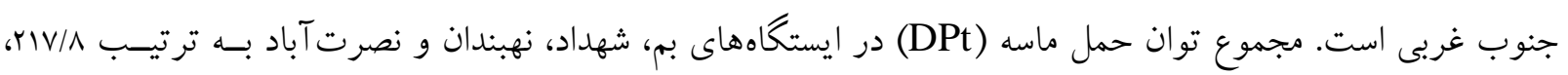

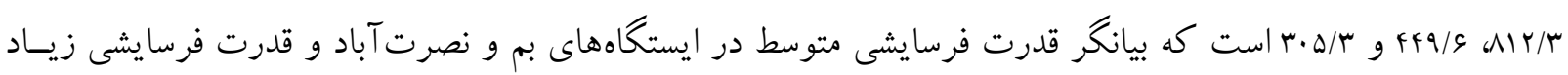

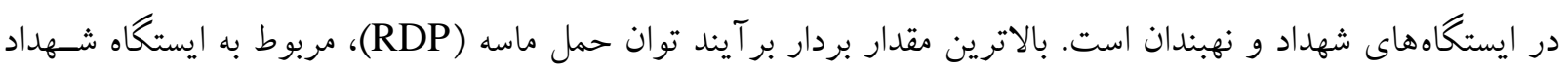

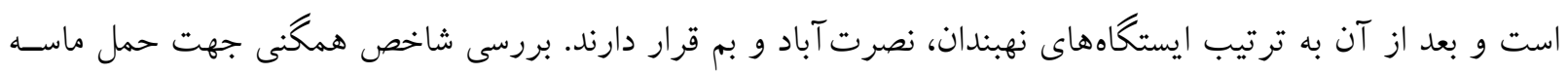

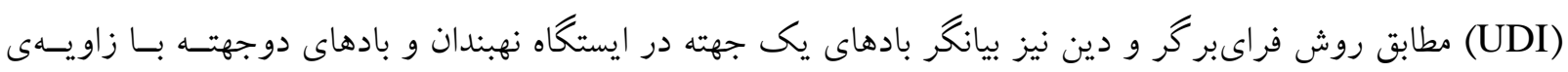

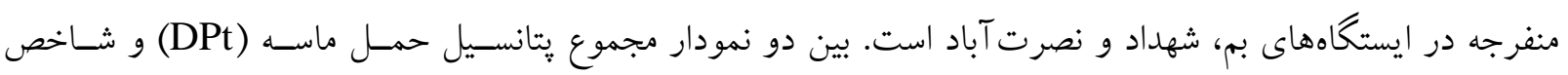

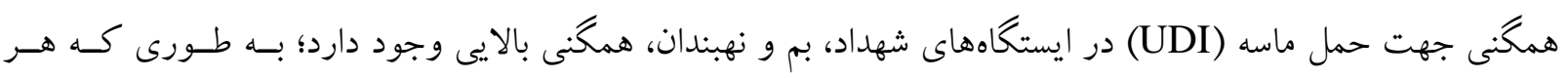
زمان شاخص UDI به يك نزديك شود و باد يك جهته باشد، شاخص توان حمل ماسه نيز اعداد بالاترى را نشان مسى

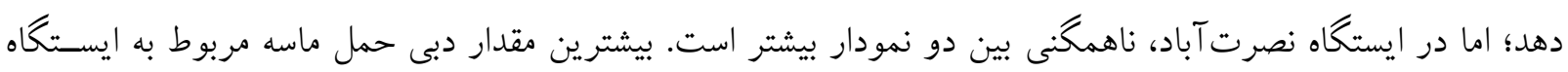

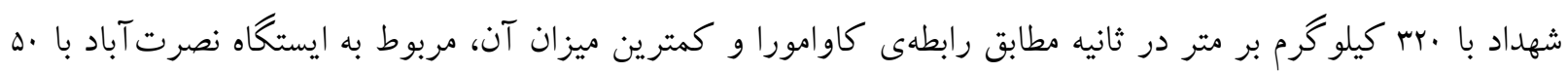

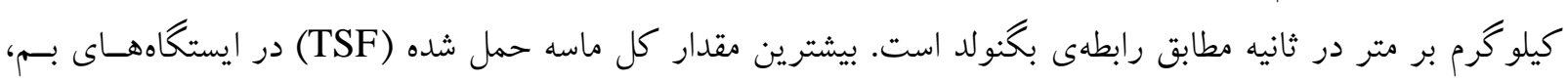

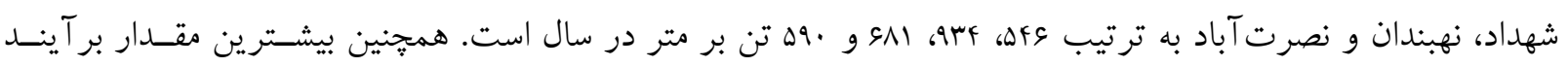

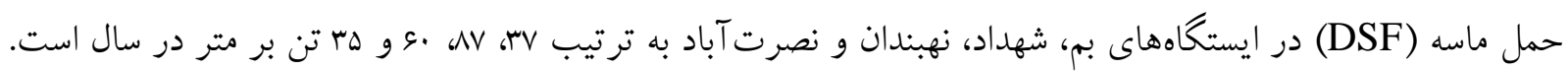

\section{منابع}

1. Al-Awadhi, J. M., \& A. M. Al-Dousari., (2013). Morphological characteristics and development of coastal nabkhas, north-east Kuwait. International Journal of Earth Sciences. 102(3), 949-958.

2. Fryberger, S. G.; Dean, G.; \& E. McKee, 1979. Dune forms and wind regime, A Study of Global Sand Seas, US Geological Survey Professional Paper, 1052, 137-170.

3. Hereher, M. E., 2018. Geomorphology and drift potential of major aeolian sand deposits in Egypt, Geomorphology, 304, 113-120. 
4. Lancaster, N., 1995. Geomorphology of desert dunes: Psychology Press.

5. Lettau, K., 1978. Experimental and micrometeorological field studies of dune migration, Exploring in the World's driest climate, 110-147.

6. Livingstone, I.; Bristow, C.; Bryant, R. G.; Bullard, J.; White, K.; Wiggs ,G. F.; \& D. S. Thomas, 2010. The Namib Sand Sea digital database of aeolian dunes and key forcing variables, Aeolian Research, 2(2-3), 93-104.

7. Louassa, S.; Merzouk, M.; \& N. K. Merzouk, 2018. Sand drift potential in western Algerian Hautes Plaines, Aeolian Research, 34, 27-34.

8. Nazari Samani, A. A.; Dadfar, S.; \& A. Shahbazi, 2013. A Study on Dust Storms Using Wind Rose, Storm Rose and Sand Rose (Case Study: Tehran Province), Desert, 18(1), 9-18. doi:10.22059/jdesert.2013.36271(in persian)

9. Okin, G.; Gillette, D.; \& J. Herrick, 2006. Multi-scale controls on and consequences of aeolian processes in landscape change in arid and semi-arid environments, Journal of arid environments, 65(2), 253-275.

10. Pearce, K. I., \& I. J. Walker., (2005). Frequency and magnitude biases in the 'Fryberger'model, with implications for characterizing geomorphically effective winds. Geomorphology. 68(1-2), 39-55.

11. Skidmore, E., 1987. Wind-erosion Direction Factors as Influenced by Field Shape and Wind Preponderance 1, Soil Science Society of America Journal, 51(1), 198-202.

12. Sterk, G., 2000. Flattened residue effects on wind speed and sediment transport, Soil Science Society of America Journal, 64(3), 852-858.

13. Toy, T. J.; Foster, G. R.; \& K. G. Renard, 2002. Soil erosion: processes, prediction, measurement, and control: John Wiley \& Sons.

14. Tsoar, H., 1994. Bagnold, RA 1941: The physics of blown sand and desert dunes. London: Methuen, Progress in physical geography, 18(1), 91-96.

15. Whicker, J. J.; Pinder, J. E.; \& D. D. Breshears, 2006. Increased wind erosion from forest wildfire: implications for contaminant-related risks, Journal of Environmental Quality, 35(2), 468-478.

16. Yang, H.; Cao, J.; \& X. Hou, 2019. Characteristics of Aeolian Dune, Wind Regime and Sand Transport in Hobq Desert, China, Applied Sciences, 9(24), 5543.

17. Zhang, C. L.; Zou, X. Y.; Gong, J. R.; Liu, L. Y.; \& Y. Z. Liu, 2004. Aerodynamic roughness of cultivated soil and its influences on soil erosion by wind in a wind tunnel, Soil and Tillage Research, 75(1), 53-59.

18. Zhang, Z.; Dong, Z.; \& C. Li, 2015. Wind regime and sand transport in China's Badain Jaran Desert, Aeolian Research, 17, 1-13.

19. Zhang, Z.; Wieland, R.; Reiche, M.; Funk, R.; Hoffmann, C.; Li, Y.; \& M. Sommer, 2012. Identifying sensitive areas to wind erosion in the Xilingele grassland by computational fluid dynamics modelling, Ecological informatics, 8, 37-47.

20. Parsamehr, A., \& Z. Poorkhosravani., (2017). Analysis of erosive winds and the study of wind sediment carrying capacity in desert areas of Isfahan province. Iranian Range and Desert Research. 23(4), 832-842. (in persian)

21. Fatahi et al., 2002. Evaluation and preparation of total desertification risk map by FAOUNEP method (Case study: Qomroud watershed), 2002. 17(4). (in persian)

22. Saremi Naeeni, M. A., 2017 Estimation of frequency, speed and direction of erosive winds and generating dust storms and fine dust in Yazd province using windrose, storm rose and sand rose analysis, Desert Management, 4(8), 96-106. (in persian)

23. Zamani et al., 2019. Wind erosion analysis of synoptic stations in Kerman province using wind rose, storm rose and sand rose, Journal of Soil Management and Sustainable Production, 9(2), 23-43. (in persian) 


\title{
Analysis of wind erosion and transport potential of quick sands located in the territory of Lut desert
}

\author{
Sasan Zangenehtabar: Ph.D Student in Geomorphology, Physical Geography Department, Faculty of \\ Geography, University of Tehran, Tehran \\ Mehran Maghsoudi": Associate professor, Physical Geography Department, Faculty of Geography, University \\ of Tehran, Tehran \\ Fatemeh Menbari: Ph.D Student in Geomorphology, Physical Geography Department, Faculty of Literature and \\ Humanities, University of Razi, Kermanshah \\ Mina Hoseini:Master of Geomorphology, Physical Geography Department, Faculty of Literature and \\ Humanities, University of Razi, Kermanshah
}

Article History (Received: 2021/05/27

Accepted: 2021/05/26)

\section{Extended abstract}

\section{1-Introduction}

Arid and semi-arid regions of the world cover more than $30 \%$ of the earth's surface. Wind, as one of the erosive agents of the earth's surface, causes the transport of sand and deformation in arid areas. Wind erosion is directly related to wind speed. The higher the wind speed is above the threshold value, the more increase in wind speed. This issue increases wind erosion and thus, it intensifies wind erosion. The Iranian plateau is one of the most sensitive areas of the world to wind erosion due to its location on the arid belt of the northern hemisphere. The Lut Desert is one of the most active places for changes in wind speed and direction with its huge volume of sand masses. The eastern part of this region, which includes the largest sand mass in Iran, namely Yalan sand, is dominated by 120-day winds, which doubles the importance of studying winds and its shaping role in the wind season. The main purpose and assumption of this study is to analyze the frequency of erosive winds and estimate the potential and final direction of sand transport flow in the Lut plain and to investigate its relationship with the geomorphology of existing wind forms using time series data of wind direction and speed recorded in Synoptic stations are located around this plain.

\section{2-Methodology}

In this study, in order to analyze the wind situation and study the erosive winds in the Lut plain, the available meteorological data for 4 synoptic stations around this plain were used. WRPLOT view 7 software was used for statistical calculations of wind and drawing of wind rose. Sand Rose Graph 3 software was also used to draw the sand rose of the stations around Lut plain due to the high volume of calculations. To calculate the values of sand transport potential (DP) in different geographical directions, the Freiberger-Dean relationship based on the basic equations of Begnold and Leto-Leto was used. From the sum of DP values in different directions, the total sand carrying capacity (DPt) is obtained and in fact it is an indicator that represents the total wind energy to carry sand to the desired station. RDP stands for the amount or size of the output vector (resulting vector) of sand carrying capacity, which is obtained by summing the DP values in 8 or 16 different directions and shows the final status of sand transport in the study area. RDD indicates the net direction of sand movement (result vector direction) during the year, month or season. In order to determine the amount of sand

\footnotetext{
* Corresponding Author: maghsoud@ut.ac.ir
} 
transferred per unit time, a unit of width is used from the equations presented by Begnold, Xing, 1953, Kawamura, 1964, Hesu, 1973 and Leto-Leto, 1978.

\section{3- Results}

At Shahdad station, about $40 \%$ of the winds blow from the north, north-northwest and northnortheast, and the rest of the winds often blow from the east and west. At Nehbandan station, about $20 \%$ of the winds blow from the north and northeast, and the rest of the winds have a great variety in the directions. At Bam station, about $36 \%$ of the winds blow from the west and west-northwest and the rest of the wind blows from the north and its surroundings. At Nusratabad station, about $31 \%$ of the winds blow from the east and southeast, about $27 \%$ of the winds from the west and northwest, and the rest of the winds from other directions with great variety. The results of annual hurricanes indicate that winds with north, north-northwest and north-northeast are the dominant winds in Nehbandan and Shahdad stations. At Bam station, in addition to the north directions, these winds also blow from the west and west-northwest directions. At Nusratabad station, there is a great variety of wind directions, but unlike other stations, the wind does not blow from the north. Analysis of net direction of sand movement (RDD) of the studied stations shows that the direction of sand movement in Bam and Shahdad stations is south-southeast, in Nehbandan station to the south and in Nusratabad station is to north-northeast. The analysis of the direction of movement of the sandrose shows the complete correspondence with the hurricane rose of the studied stations. Total sand carrying capacity (DPt) indicates moderate erosion power for Bam and Nusratabad stations and high erosion power for Shahdad and Nehbandan stations. The highest value of vector output of sand carrying capacity (RDP) is related to Shahdad station, followed by Nehbandan, Nusratabad and Bam stations, respectively. For Shahdad, Bam and Nehbandan stations, the maximum amount of one-way winds occurs in autumn and in Nusratabad station in late winter and spring. The maximum amount of sand flow for Bam, Shahdad, Nehbandan and Nusrat Abad stations is 165, 320, 233 and $202 \mathrm{~kg} / \mathrm{m} / \mathrm{s}$, respectively.

\section{4- Discussion \& Conclusions}

The results indicated that in Shahdad and Nehbandan stations located in the northern half of Lut plain, most of the winds blow from the north, but in Bam and Nusratabad stations located in the southern half of Lut plain, most of the winds are concentrated towards Lut. The highest percentage of occurrence of winds above the threshold speed for Shahdad, Nehbandan and Bam stations occur in summer and the highest percentage of occurrence in Nusratabad station is related to spring. Analysis of net direction of sand movement (RDD) shows that the direction of sand movement in Bam and Shahdad stations is to the south-southeast, in Nehbandan station is to the south and in Nusratabad station is to the north-northeast. Total sand carrying capacity (DPt) indicates moderate erosion power for Bam and Nusratabad stations and high erosion power for Shahdad and Nehbandan stations. The highest value of vector output of sand carrying capacity (RDP) is related to Shahdad station, followed by Nehbandan, Nusratabad and Bam stations, respectively. The study of sand homogeneity index (UDI) indicates one-way winds for Nehbandan station and two-way winds with aperture angle for Bam, Shahdad and Nusratabad stations. The highest flow rate of sand is related to Shahdad station with $320 \mathrm{~kg} / \mathrm{m} / \mathrm{s}$ and the lowest is related to Nusratabad station with $50 \mathrm{~kg} / \mathrm{m} / \mathrm{s}$.

Key Words: Wind, Sand Carrying Potential, Erosion, Lut. 